مجلة جامعة الملك عبدالعزيز: الآداب والعلوم الانسانية، م29ع3 ص ص: 282- 308 (2021م)

DOI:10.4197/Art.29-3.10

\title{
تطوّر النموذج العلمي اللساني: قراءة في الاتِجاه البنيويّ والتوليديّ والوظيفيّ
}

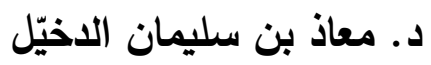 \\ أستاذ اللسانيّات المساعد في قسم اللغنة العربّيّة وآدابها \\ بكلية اللغة العربية والدراسات الاجتماعيّة في جامعة القصبي. \\ البريد الإلكتروني: msdkhiel@qu.edu.sa
}

مستخلص. قامت الدراسة على إظهار التحوّلات الإبستمولوجيّة الواقعة في علم اللسانيّات ضمن حدود العلاقة الرابطة

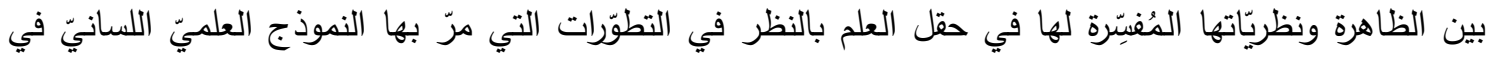

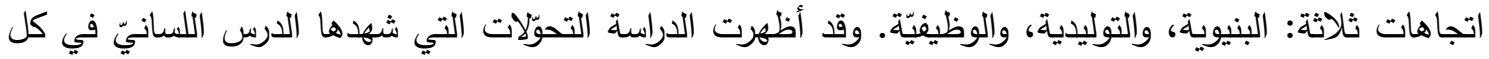

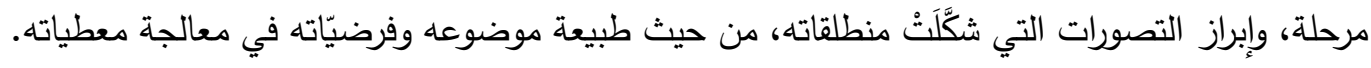

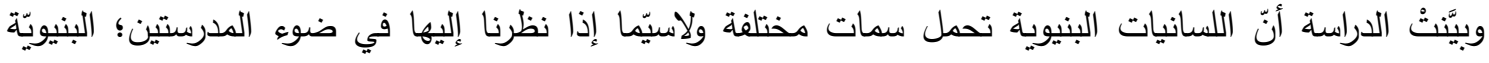

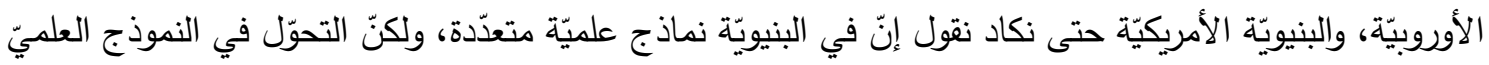

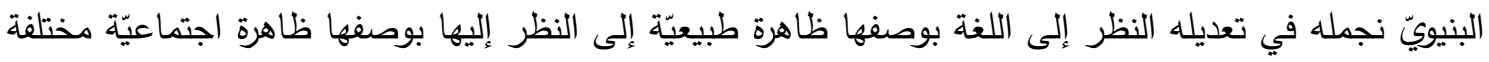

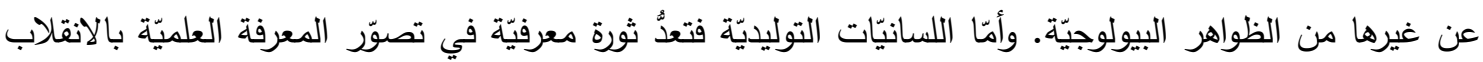

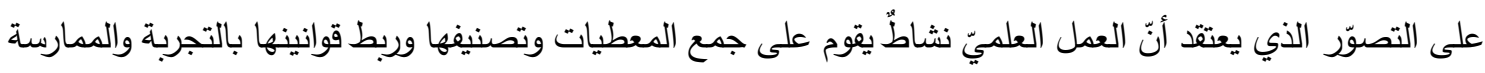

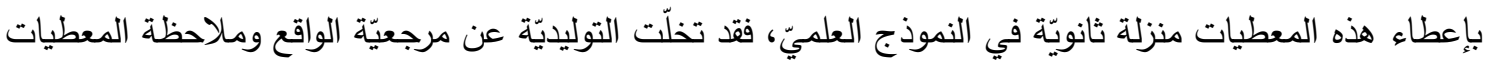

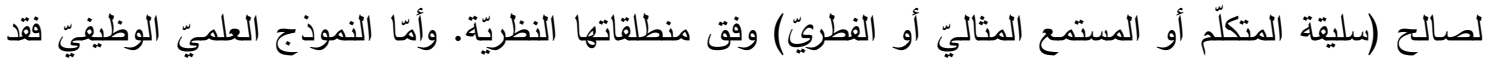

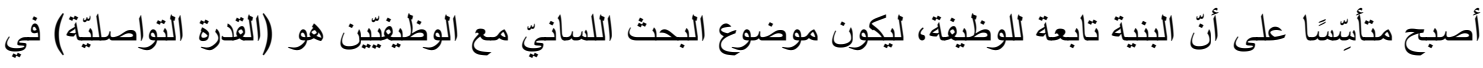

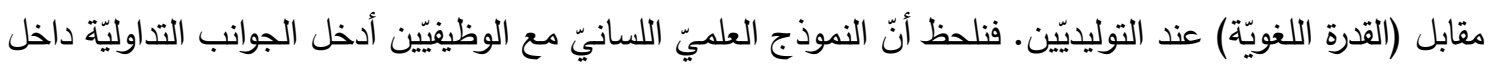

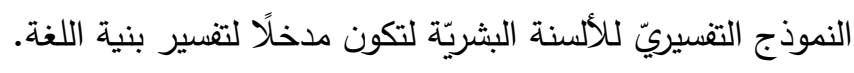

$$
\text { الكلمات المفاتيح: لسانيات - نموذج علميّ - بنيويّة - توليديّة - وظيفيّة. }
$$

بين الظاهرة ونظريّاتها الدُفِّبرة لها في حقل العلم؛ وفئه فالعلم قائم على حوار دائم بين العقل الذي يلاحظ فئرة الظاهرة ويعيد صياغتها في بنيات منطقيّة وبين

تقوم هذه الدراسة على إظهار التحوّلات الإبستمولوجيّة الواقعة في علم اللسانيّات ضمن حدود العلاقة الرابطة 
يتبنّى العماء أدوات جديدة، ويتطلّعون بأبصارهم صوب اتجاهات جديدة. بل وأهمّ من ذلك أنّ العلماء وله باء إبان الثورات يرون أثياء جديدة ومغايرة عندما ينظرون

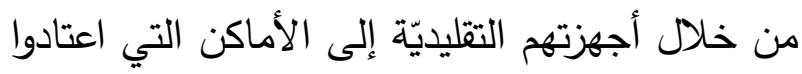
النظر إليها وتفحّصها قبل ذلك. ويبدو الأمر وكأن الجماعة العلميّة المتخصّصة قد انتقلت فجأة إلى الى كوكب آخر حيث تبدو الموضوعات التقليديّة في ضوء مغاير وقد ارتبطت في الوقت ذاته بموضوعات أخرى

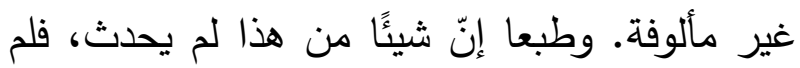

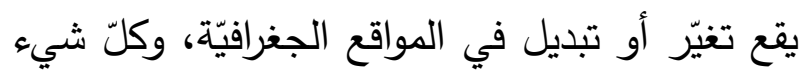
من شؤون الحياة العاديّة يجري كعادته خارج المعل لهل على نحو ما كان تمامًا. ومع هذا فإنّ التحوّلات التي لتوني طرأت على النماذج الإرشاديّة تجعل العلماء بالفعل

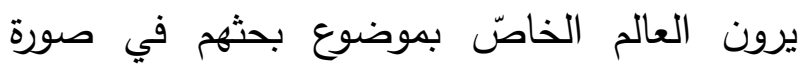

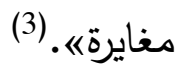
وتبدو في سياق البحث اللسانيّ العربيّ إشكاليّات يواجهها البحث العلميّ حتّى شكّلتُ أزمةً للسانيّات في ليّي الثقافة العربيّة، من ذلك غياب الوعي بإيجابيّة الحصيلة المعرفيّة التي تراكمها اللسانيّات من مرحلة إلى أخرى حتى أصبح هذا الغياب غير مختلف عن

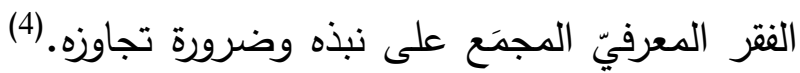
وجسَّدَ مصطفى غلفان هذا الغياب في عدم مواكبة جماعة من اللسانيّين العرب تطوّر النظريّات اللسانيّة، ولهذا المظهر تجليّات، منها: 1. يذكر بعض اللسانيّين أنّ علم اللغة يهتمّ بالمناهج العلميّة التي تقوم على الاستقراء والملاحظة والتجربة،
الظاهرة المتجمّدة في العالم الخارجيّ بما يسمح للمعرفة العلميّة أنْ تواصل تقدّمها في فهم الظواهر وتقسيرها. ولاشكََّ أنّ هذه السبيل في الدراسة توضّح آلّيّات تقدّم المعرفة العلميّة وتُظظهِر مناط القبول لنظرية علميّة ما في مرحلة معيّنة، وتسهِجُ في فهم النقود الموجّهة لها التي أثمرت ظهور نظريّة علميّة أخرى. (1) وكان علم اللسانيّات -بصفته علمًا يروم وصف الظاهرة اللغويّة وتقسيرها- واقعًا في هذا السياق، وعاش هذا العلم في الثقافة العربيّة علاقة جدليّة في تلقّيه، وفي علاقته مع الموروث اللغويّ العربيّ في حقب تاريخيّة مختلفة، وبدت في بعض المنعرجات التي حكت هذه العلاقة أقوالٌ تعيب على علم اللسانيّات ما هو من طبيعة العلم ومسلّماته؛ فعُدَّ تطوّر لعرّ علم اللسانيّات باتِّاهاته المتلاحقة نقيصة في نظر بعض الباحثين تدعو إلى نبذه والتخلّي عنه. وكان هذا ناتهات

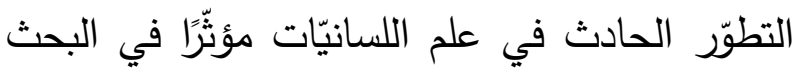
العربيّ المعاصر من جهتين؛ إحداهما أنّ الموقف من قضايا الموروث العربيّ وتخطئة إجراءاته أو تثمينها رهين هذه التطوّرات اللسانيّة، والجهة الثانية أنّ قراءة الظواهر اللغويّة العربيّة نفسها كان متعدّدًا نظير ذاك التطوّر • - - م وتهتمُ هذه الدراسة بالتطورّات التي مرّ بها النموذج العلميّ اللسانيّ (Paradigm) (2) انطلاقًا ممّا بينّه توماس كون حول طبيعة المعرفة العلميّة وتطوّراتها إذ قال: 》عندما تتغيّر النماذج الإرشاديّة (Paradigm) يتغيّر معها العالم. وانقيادًا للنماذج الإرشاديّة الجديدة الإني 
المنطق الذي يحكم تطوّرها بالإثارة إلى أهمّ التقسيرات

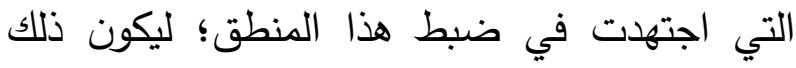

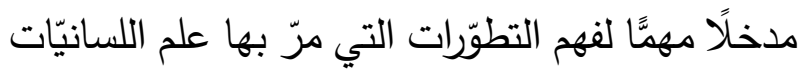

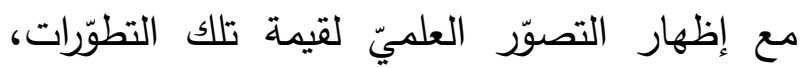
وتجلية ثمارها النظريّة والإجرائيّة في دراسة اللغة. واقتصرت الدراسة على ثلاثة اتجّاهات لسانيّة:

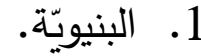

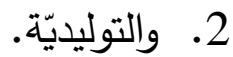

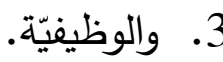

فكانت الغاية إظهار التحوّلات التي شهدها الدرس اللسانيّ في كل مرحلة من هذه المراحل الثلاث، وإبراز

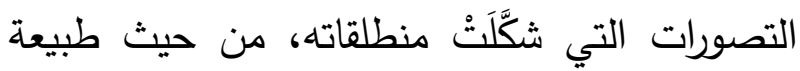
موضوعه والفرضيّات التي أسهمت في معالجة

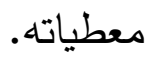

وجاءت الدراسة في أربعة مباحث تسبقها مقدّمة،

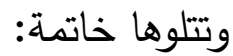

المبحث الأوّل: مدخل نظريّ: ماهيّة المعرفة العلميّة، والمنطق الذي يحكم تقدّمها. المبحث الثاني: النموذج العلميّ في اللسانيّات البنيويّة. المبحث الثالث: النموذج العلميّ في اللسانيّات

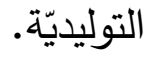

المبحث الرابع: النموذج العلميّ في اللسانيّات

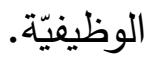
ولا يفوتني أن أشكر جامعة القصيم التي هيَّأت سبل إنجاز البحث بإتاحتها لي فرصة الاتّصال العلميّ في صيف 2019م، كما أقدّم جزيل الثكر للأستاذ
رغم أنّ هذا الطرح أصبح مُتجاوذًا منذ مدّة ليست بالقصيرة في سياق البحث العلميّ الصّرف، وفي إطار البحث اللسانيّ خاصّة. 2. ومن أمثلة ذلك أنْ يُعرّف أحد الباحثين في سبيعينيّات القرن الماضي اللغةَ بأنها ظاهرة اجتماعيّة ثقافيّة مكتسبة لا صفة بيولوجيّة ملازمة للفرد، رغم أنّ بلت

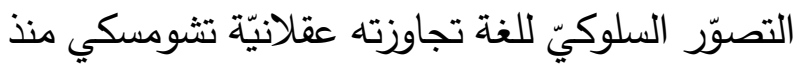
نهاية خمسينيّات القرن الماضي. 3. وأكثر التجلّيات وضوحًا ما نجده من نزعة نحو تقرير "حقائق معرفيّة ثابتة" لا وجود لها في منظومة العلم، إذ يقطع بعضهم بعدم قدرة علماء اللغة تقرير قوانين عامّة يمكن أن تنطبق على اللغات جميعها. رغم أنّ هذا القول ينطلق من النزعة البنيويّة التي تمثّل

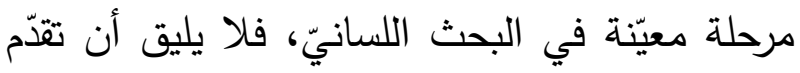

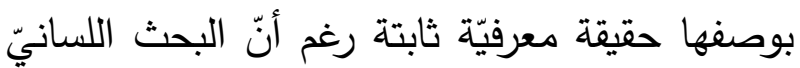
تجاوزها. (5) وقد وجدت هذه الإشكاليّات بيئة ساعدتها في النموّ والانتشار وهيَّأتها له بفعل ضعف حضور "العلم وسماته ومبادئه" في الثقافة العربيّة بصفته إطارًا منهجيًّا وفلسفيًّا ومعرفيًّا يصدر عنه الباحث العربيّ في الظاهرة البشريّة بعامّة، والباحث في الظاهرة اللغويّة العربيّة بخاصّة. وتمثّل هذه الإثكاليّات والعوائق التي تواجه البحث اللسانيّ العربيّ دوافع حقيقيّة لهذه الدراسة التي تستدعيها هذه الظروف الموضوعيّة، إذ توخَّينا فيها الابتداء ببيان سمات المعرفة العليّة، وتوضيح 
الاكتور مصطفى غلفان الذي تفضّل بمقترحاته قبل اصّيتين: 1. خاصيّة التفكير في ذاته بكونه معرفةً نقديّةً دائمة تحرير البحث ثم تفضّل بقراءته وإبداء ملاحظاته الدقيقة بعد الانتهاء منه، وأشكر كذلك الأستاذ الدكتور المراجعة.

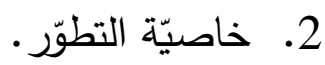
وهاتان الخاصيّتان تفسّران التقدّم العلميّ المستمر في ضروب المعرفة المختلفة. فننطلق من هذا التصوّر لطبيعة العلم للإجابة عن سؤال مهمّ:

1-2-1 كيف تتقدّم المعرفة العلميّة؟ لونج نشير ابتداء إلى أنّ مسألة الفصل بين العلوم الطبيعية

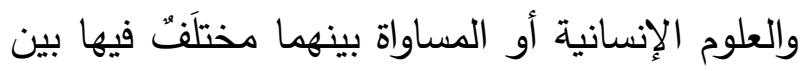
فلاسفة العلم، ولا نستطيع أن نفصل هذه الإسلية القضية عن

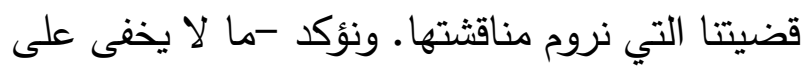
القارئ- أنّ هناك نقاشًًا واسعًا وممتدًا تاريخيَّا داخل فلسفة العلم أو داخل أحد العلوم حول مقاييس العلميّة

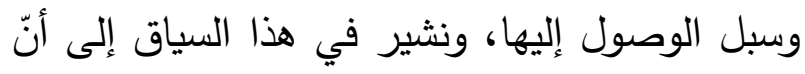

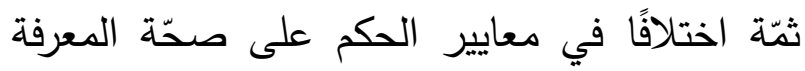
العلميّة بين مرحلة وأخرى. - معاير. وسنكتفي في هذه القضية بالإشارة المُجملة إلى التصورات المشهورة في تفسير تقدّم العلم وشرح منطقه الذي يحكمه. ويمكن أن نختزل ذلك في اتِّاهين: 1. يرى أحدها أنّ العلم يتقدّم بالمنطق التراكميّ. 2. ويرى الآخر أنّ العلم يتقدّم بالمنطق الثوريّ.

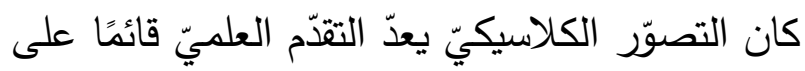
التراكم، ويمثّل ذلك ما ذكره (نيوتن) إنّه لم يستطع أن لني

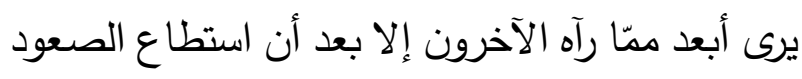
على أكتافهم. (9)

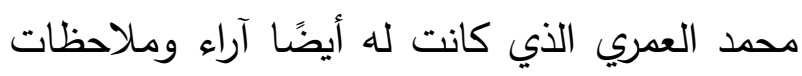
أغنت البحث وجّهته نحو وجهته النهائيّة. مدخلٌ نظريٌّ:

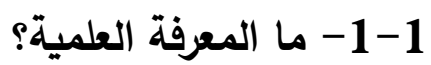
ربما شاع لاى كثير من الباحثين أو المثقين أو حتى مائ

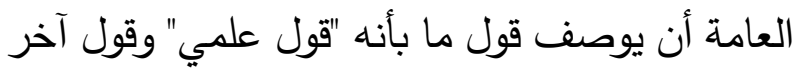
بأنه "قول غير علمي"، ولسنا متيقنين من أنّ القائل بهذا القول مدرك" لمعنى ذلك وقادر على روز الأقوال العلمية من الأقوال غير العلمية وفق معايير "علمية"

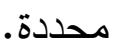
ونجد أنّ للعلم تعريفاتٍ كثيرةً يصعب جمعها في تعريف واحد؛ لأنّ العلم بطبيعته غيرُ ثابتٍ ومتطوّرٌ تحت ظروف مختلفة، من أهمّها أنّ هناك نقاشًُا ممتدًّا حول الآلّيّات والطرق المحقّقة للمعرفة العلميّة، ولكن يمكن أن نبدأ بتعريف (برتراند راسل) للعلم: إنّه النوع الذي يبحث عن القوانين العامّة التي تربط بين مجموعة من الحقائق الخاصة. (7)

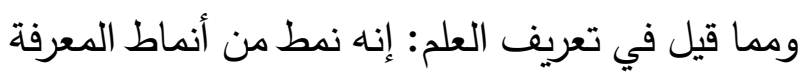
النقدية. فهو يمارس مراقبة حذرة على خطواته المنهجية الخاصة ويطبق معايير دقيقة للتأكد من صلاحيتها، ويقوم من جهة أخرى بصياغة مناهج

تمكّنه من توسيع حقل معرفته بطريقة ممنهجة. ننطلق إذن من هذا التعريف الذي يجعل للعلم 
ويعتري هذا التقسير مأخذ يتمثّل في اختصار ودون التراكميّ نجد أصحاب الاتّجاه الآخر يحاولون تجاوز إطالة- في أنّ القول بالتفسير التراكميّ يقتضي القول هذين الإثكالين، ومن تلك المحاولات التفسيرُ الذي لتئي يمليه علينا ما أضافه (كارل بوبر ) في فلسفة العلم بأنّ الأن التقدّم العلميّ يقع حين تحلّ نظريّة قابلة للاحض محلّ

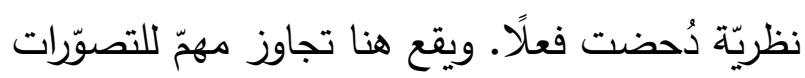
السابقة، إذ إنّ المعرفة العلميّة قبل (كارل بوبر) كانت محكومة بمنطق التبرير المتمثل في الاستقراء Induction (كارناب) ومدرسة فيينا، أي البحث عمّا يثبت صحّة المعرفة العلميّة وتميّزها، ثم جاء (كارل بوبر) بمعيار قابلية الدحض Falsifiability، فأصبحت المعرفة

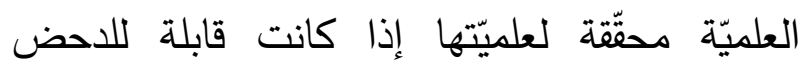
والتكذيب لتعيين القصور والخطأ لتحلّ محلّها -في يوم ما- معرفة أكفأ. (10) ولا يكون ذلك ولك إلا بتعيين

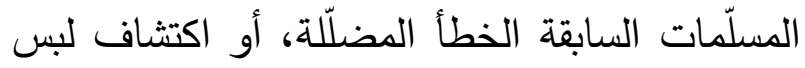
وغموض بعض المصطلحات المعتمدة في الإطار النظري السابق، ويعني هذا أنّ كلّ إطار نظريّ مهما

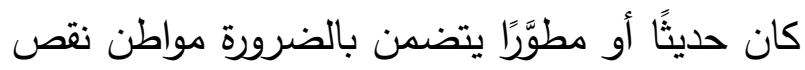
ذاتية فيه يتعين على اللاحقين مراقبتها لتعديلها أو بورئان دحضها.

ونلحظ في هذين التصوّرين أنّ الأوّل منهما يؤول

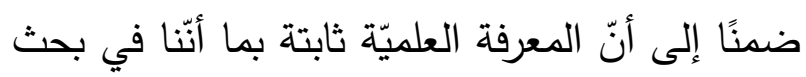
دائم عمّا يثبت صحّتها وقوّتها، وهذا مأخذ واضح.

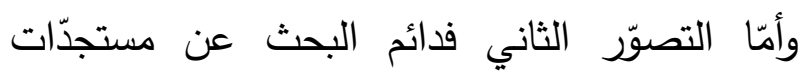
المعرفة العلميّة؛ لأنّ المعرفة لا تكتسب صفة العَّة العليّة وفق منطقه إلا إذا كانت ممكنة المراجعة والتقنيد، فهي لان لهعه لهنه

بأمرين إشكاليّين، هما:

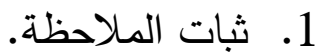

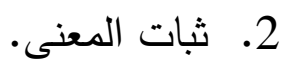
لأنّ القول بالتراكم يقتضي صحّة التقسير العلميّ في

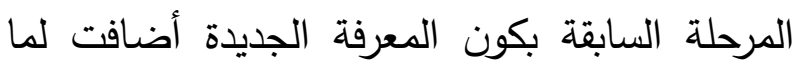
سبقها من معرفة وراكمت بناء جديدًا على أساسه. وكان هذا التصوّر محلَّ نقد عند فلاسفة العلم المحدثين لأمرين: - المان 1. أوّلهما أنّ تاريخ العلم يسير خلاف هذا التصوّر في حقيقته فتقدُّم المعرفة كان تقدُُمًا إحلاليَّا لا تراكميَّا؛ لذلك كان تجاوز التفسير الأرسطيّ بعد سيادته قرونًا طويلة مع الثورة العلميّة في القرن السابع عشر قائمًا على الإمساك بالمعطيات نفسها التي كانت متاحة من قبل مع إعطائها معنى جديدًا بجعلها في نظام جديد من علاقات المعطيات بعضها ببعض، فيكون -إذن ما وقع تجاوذًا، وثورة معرفيّة وليس تراكمًا.

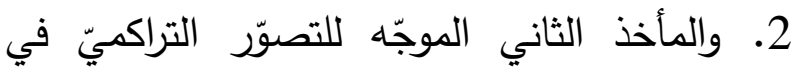
تفسير تقدّم المعرفة العلميّة أنّه تصوّر غير متّّق مع طبيعة بناء المعنى من ملاحظة الظواهر المدروسة، إذ إنّ لكلّ نظريّة تجربتها الخاصّة، فلا تداخل بين

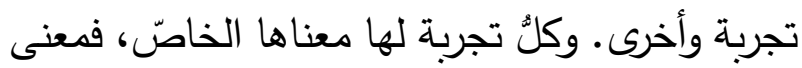
القضايا الملاحظة مرتبط بمنطلقاتها النظريّة، فلا وجود لمعطياتٍ علميّة خارج إطار نظريّ محدّد. وفي سياق هذه النقود التي وُجّهت لأصحاب التقسير 
بمقتضى العلاقة التبادليّة المنعقدة بين النموذج العلميّ وظواهر الواقع ومعطياته إذ تصل العلاقة بينهما إلى انسداد وأزمة، فتحدث قفزة ثوريّة تكون نفسها نقطة بدء جديدة لتطوّر تراكميّ آخر. نلحظ إذن أنّ (توماس كون) يميّز في سياق تفسيره للتقدّم العلميّ بين تطوّر العلم العادي ونموّه داخل إطار النموذج القياسيّ للعلم الذي يقبله المجتمع العلميّ في مرحلة ما، وبين تطوّر العلم الثوريّ إذ يتحطّم النموذج العلميّ ليحلّ محلّه نموذج قياسيّ ذو أطر مختلفة.

ونشير في هذا السياق إلى التصوّر الذي يجب أن ننطلق منه في تصوّرنا للعلاقة بين الظاهرة ووصفها العلميّ؛ فإنّ التسليم بكون العلم غيرَ قارِ يقتضي أن يكون الوصف العلميّ لظاهرة ما قريبًا له في حقيقته دون أن نعتقد المماثلة بينهما في أيّة مرحلة من المراحل، فكلّما تطوّر العلم وتقدّمت النظريّات اقتربنا إلى الحقيقة، فالعلم يتقََّّم على الدوام مقتربًا من الحقيقة بحسب ما يراه كارل بوبر، ويقودنا هذا إلى معيار النزعة التكذيبية في روز الأقوال العلميّة عن غيرها، إذ تُعدُّ النظريّات السابقة التي حلَّت نظريّاتُّ أخرى محلَّها نظريّاتٍ كاذبةً -بتأويلٍ ما- في ضوء نظريّاتتا الراهنة، وأمّا النظريّات الراهنة فهي نظريات قابلة للتكذيب والدحض إذا أردنا أن نجعلها في دائرة العلم. وتكون بذلك النظريّاتُ العليّة اللاحقة عندهم أكثرَ اقترابًا إلى الحقيقة دن النظريّات السابقة وإن كانتا كاذبتين؛ من ذلك المقارنة على سبيل التمثيل بين
في مواجهة دائمة مع الوقائع والتجربة. وفي سياق التفسير الثوريّ لطبيعة التقدّم العلميّ يحاول (توماس كون) أن يوجٍَ صياغة أكثر تصالحًا مع أصحاب التفسير التراكميّ، إذ يميّز بين تقدُّم العلم القياسيّ والاعتياديّ من جهة وبين المراحل الثوريّة في هذا التقدّم من جهة أخرى، ويتّضتح تفسيره بافتراضها أنّ العلم في تاريخه يصحّح أخطاءه مع مرور الزمن بالتتقيح المعرفيّ المستمرّ لمضمون النظريّات ضمن إطار النموذج القياسيّ للعلم، فهنالك عدد من الصيخ للنظريّات التفسيريّة التي تؤول وتختزل في نموذج إرشاديّ واحد يحتويها كما تختزل صيغة (فعل) عددًا كبيرًا من الأفعال، نحو: نصر وذهب وباع وقال ... • ويقول لنا تاريخ العلم -من وجهة نظر (كون)- إنّ النماذج العليّة تبدو في مرحلة معيّنة غير قادرة على التعاطي مع الظواهر وتفسيرها فيقع التخلّي عن النموذج القديم إلى نموذج علميّ جديد وتحدث ثورة في العلم تغيّر طبيعة النظرة إلى العالم ثم تقبل الجماعة العلميّة هذا النموذج الجديد، وتكون له السيادة شييًا فشينًا مع تلاشي النموذج العلميّ القديم. وينبثق من مرحلة الانتقال من النموذج العلميّ القديم إلى النموذج العلميّ الجديد تقليد جديد للعلم القياسيّ في لحظة تغيير ثوريّة؛ لأنّها إعادة بناء المفاهيم الأساسيّة بصورة كليّة بإحداث العلماء تغيُرًا في مخطَّطات تفكيرهم ليروا الأشياء القديمة بطريقة جديدة، فتكون روح العلم بهذا التصوّر تصحيح المعرفة، وتوسيع نطاقها. ويكون التقدم التراكمي مُؤديًا إلى قفزات ثورية 
المراحل التي كانت الدراسة اللغويّة فيها داخلة في الحقول المعرفية الأخرى تأثًُّا بها أو تأثيرًا فيها بعد أنْ كانت قبل ذلك أشبه ما تكون بالتأمّلات الفلسفيّة التي تحاول فهم ظاهرة اللغة وتفسيرها. كانت نهايات القرن الثامن عشر وبدايات القرن التاسع عشر منعرجًا مهمَّا في دراسة اللغة في الغرب، ومنطلق ذلك كان ما اكتثفه علماء اللغة -بعد اكتثافهم اللغة السنسكريتيّة- من وجود تثابهات بين لغات متعدّدة، كاللغة الإغريقيّة واللغة اللاتينيّة واللغة السنسكريتيّة. وكانت هذه الملاحظات التي احتفى بها اللغويّون آنذاك واقعة تحت تأثير حفاوة علميّة بما حقّقه

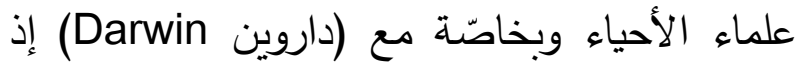
حاولوا تنسير الظواهر المختلفة في الوجود الواقعيّ بقانون التطوّر • وبما أنّ هذا القانون انطلق من أحد العلوم الطبيعيّة هو علم الأحياء فإنّ علماء اللغة حينئذٍ عَدُوا اللغة ظاهرة طبيعيّة تناظر الحيوانات، والنباتات، وغيرها من ظواهر الطبيعة؛ فافترضوا أنها -أي اللغة، ولئهن يجري عليها ما يجري على الظواهر الطبيعيّة. لذلك تكون اللغة خاضعة لقانون التطوّر فهي ظاهرة تتشكّل وفق قوانين محدّدة، وتخضع للتطوّر ثم الانقراض التدريجيّ. ونجد مظاهر ذلك فيما أنتجته اللسانيّات التاريخيّة كالقول بالعائلات اللغويّة، وغيرها.

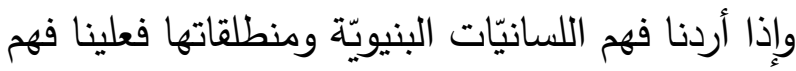
الجوانب التي رأى اللسانيّون فيها قصورًا في الاتّجاه التاريخيّ، ومن أهمّ هذه النقود أنّ هناك خطاً في تتزيل ظاهرة اللغة ضمن عالم الوجود أدّى إلى خطاً في
نظريتيّ (غاليلو غاليلي) و(نيوتن) رغم أن كليهما قد

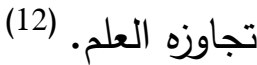
ومن البدهيّات في الساحة العلميّة ما أحدثه (كوبرنيكوس) و(كيبلر) و(غاليلو غاليلي) على سبيل التمثيل من تحوّلات في تصوّر طبيعة الكون وتبديد الاعتقاد بمركزيّة الأرض إلى القول بمركزيّة الثمس.

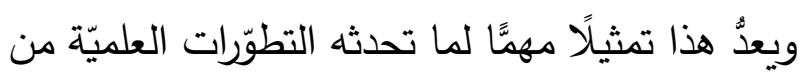

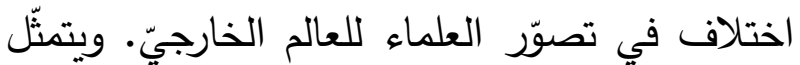
هذا التحوّل في التصوّرات كذلك في خرائط العالم التي أنجزتها الأمم في العصور القديمة، وما لحق هذه الخرائط من تعديلات وتحوّلات بعد ذلك حتى وقتنا الحاضر • إنّ الظاهرة المدروسة قارّة وثابتة لم تتغيّر ولكنّ التغيّر يحدث في تصوّرات العلماء للظاهرة تبعًا لنتائجهم التي يصلون إليها بعد دراساتهم ومحاولات تطويرها المستمرّة بالوسائل العليّة المعروفة.

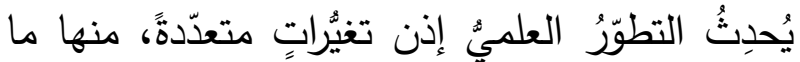
ذكرناه آنفًا من التغيّر في تصوّر ظاهرةٍ ما، ومنها

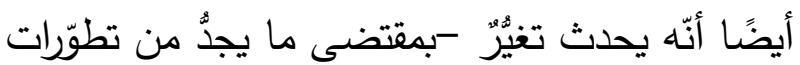
علميّة- في المادة المدروسة، فيكون هنالك توسيع للمادة التي يدرسها الباحث أو تضييق، فتدخل ظواهر لم تكن تدرس، أو تخرج ظواهر كانت ضمن الاهتمام

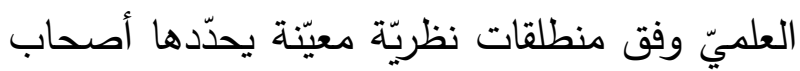
ذلك العلم. النموذج العلميّ في اللسانيّات البنيويّة(13): اختلف اللسانيّون في تحديد المرحلة التي تُعدُّ البداية الحقيقية لعلم اللسانيات، ولكن يمكن أنْ نتوقّف عند 
التي اطّلعوا عليها في وصف ألسنتهم. إضافة إلى

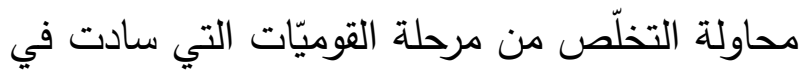
القرن التاسع عشر وما تركته من آثار في الدرس اللغويّ. فكان ذلك ابداية مرحلة جديدة تميّزت بالرغبة

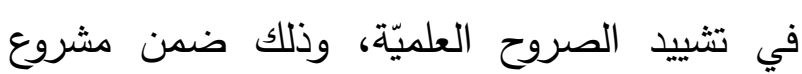

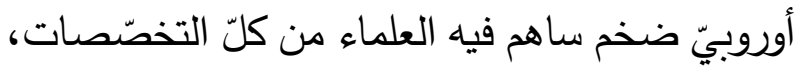

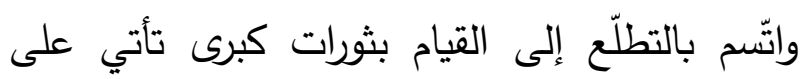
الموروث إلا ما كان يخدم هذا الهدف؛ فثاهدنا ثورات

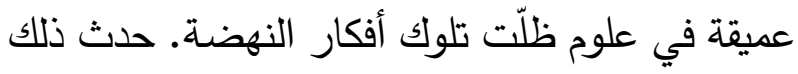
في الفيزياء والكيمياء والفلك والرياضيّات، وفي المنطق وعلوم اللغة وعلوم المجتمع وعلم النفس وغيرهاه. (17) وكان من أهمّ مظاهر تلك الفترة التاريخيّة الرغبة وعنة الملحّة لدى المشتغلين بالعلوم في ضبط حدود كلّ علم لتجاوز ما كان سائدًا في الدراسات التقليديّة من التباس وتداخل بين العلوم؛ لذلك اهتمّ دي سوسير بضبط حدود علم اللسانيّات ورسم غاياته، إذ نجد أنّه كان يرغب في الارتقاء بعلم اللسانيّات إلى مصاتّ العلوم الصحيحة بما لها من مبادئ كونيّة ليتجاوز بذلك

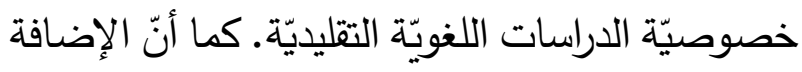
التي ألَّ عليها دي سوسير تتمثّل في فلكّ الالتباس الإسناس

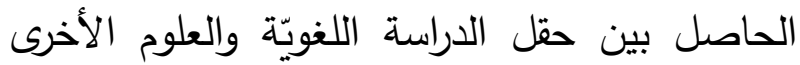
الملاصقة في الدراسات السالفة؛ لذلك اهتمَّ بالتمييز

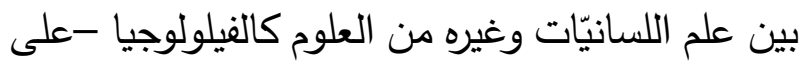
سبيل التمثيل-، فهو -أي الفيلولوجيا- يأخذ معطيات اللغة وسيلة لغاية أخرى متمثّة في دراسة حضارات الأمم؛ لذلك أصبحت عدد من القضايا من قبيل:
فههها؛ لأنَّ التاريخيّين انطلقوا من فرضيّة انتماء اللغة إلى عالم الطبيعة فطبَّقوا عليها قوانين الظواهر الطبيعيّة، فانتهى ذلك بهم إلى افتراض نتائج تفسيريّة مخالفة للظواهر المدروسة، إضافة إلى أنَّ الاهتمام

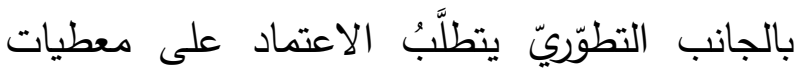
الماضي وبناء الفرضيَّات عليها؛ لذلك يصعب اختبارها لمعرفة قوّتها التفسيريّة. (14) نستطيع إذن أن نحدّد مظاهر القصور التي خلَّفها الدرس اللغويّ التقليديّ، والاتجاه التاريخيّ -من وجهة نظر اللسانيّين البنيويّين - بالقلق من النتائج التي وصل إليها أسلافهم وتثكيكهم في سلامتها. لذلك قال دي سوسير : اإنّ موضوع الألسنيّة الحقيقيّ والوحيد إنّما هو دراسة اللغة في ذاتها ولذاتهاه(15)، وسبقه في هذا التصوّر (فرانسيس بيكون) إذ رأى أنّ المعرفة العلميّة

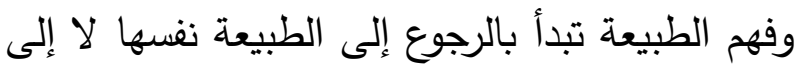

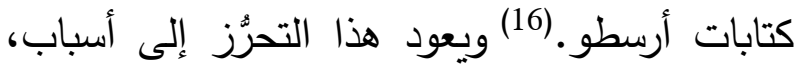
أحدها ذاك الظرف التاريخيّ الذي واجه فيه الإنسان في القرن السادس عشر آنذاك صدمات معرفيّة بعد الطدي أحداث تاريخيّة متعدّدة أحدها الكثوف الجغرافيّة، فجعته يراجع مسلّماته ويبحث عن سبل جديدة تعينه على الوصول إلى الحقيقة العلميّة بشكل صحيح وموضوعيّ. وبعد هذا نجد في حقل اللسانيّات أنّ لإن مسألة (الموضوعيّة) أصبحت هي الهاجسَ الذي سيطر على الساحة العلميّة في القرن العشرين انطلاقًا من ظرف تاريخيّ اكتشف فيه اللسانيّون -إذا أردنا أن نكتفي بهذا الحقل العلميّ- أخطاء الأنحاء التقليديّة 
التفاضل بين اللغات خارج حدود علم اللسانيات؛ لأنها إلى نتائج علميّة، ويعود هذا التصوّر البنيويّ إلى فرضيّة رئيسة تُسيّر أعمالهم وهي أنّ المعرفة العلميّة خارجة عن حدود العلم الذي ضبطه البنيويّون وأشرنا كامنة في معطيات الواقع اللغويّ نفسها. إليه سالثًا. ونجد كذلك أنّ من الأسس التي قامت علئ عليها اللسانيّات البنيوية الرفض التامّ للجانب التفسيريّ، فالعلم عندهم التين مقتصر على وصف الظواهر كما ندركها.(18)وقد كان

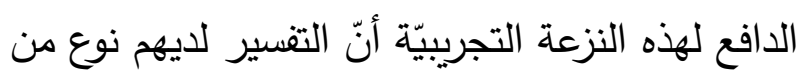
أنواع الميتافيزيقا والرجم بالغيب، وهذا ممّا استبعده البنيويّون حتى تكون نتائجهم وأحكامهم موضوعيّة ولئية ليتجاوزوا القصور الذي كان يشوب الدراسة اللغويّة قبلهم.

وفي الوقت نفسه نجد أنّ البنيويّين يوسّعون المعطيات

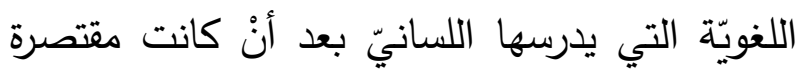

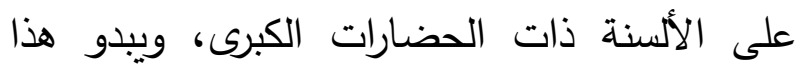
واضحًا في قول دي سوسير : "إنّ مادّة الألسنيّة تتكوّن بادئ ذي بدء من جميع مظاهر الكلام البشريّ سواء

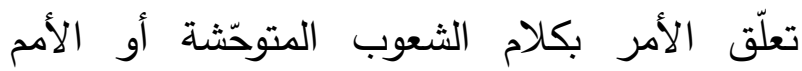

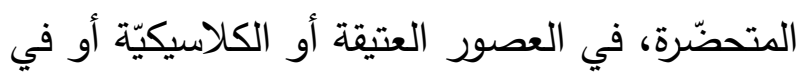
عصور الانحطاط. والمعتبر في كلّ عصر من هذه

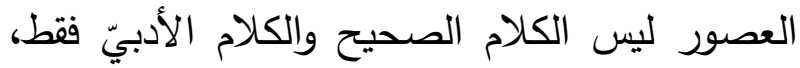

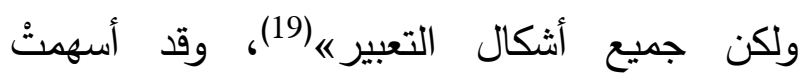
اللسانيّات البنيويّة في أمريكا خاصّة بإغناء البحث

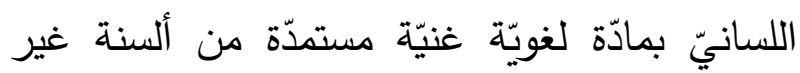

هنديّة-أوربيّة. (20)

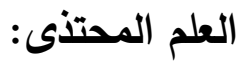

نشير ابتداء في هذا السياق إلى أنّ دي سوسير -كما وقد كان هذا التصوّر لطبيعة علم اللسانيّات لاى لإ البنيويّين باعثًا لإجابات جديدة عن أسئلة سابقة، وكانت الأسئلة تتلخّص حول سؤال كبير : كيف نتجنّب قصور الدراسات اللغويّة التقليديّة والدراسات التاريخيّة ونسلك سبيل المعرفة اللسانيّة

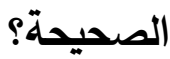
وكانت الإجابة عن ذلك تتطلّب في نظرهم إعادة النظر في المنهج المفترض اتّباعه في دراسة اللغة، وكذلك

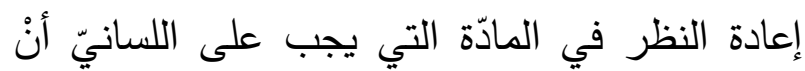
يستقي منها اللغة؛ لذلك طرح في اللسانيّات البنيويّة سؤالان: - مأن

1. ما الوقائع اللغويّة التي ينبغي اعتمادها؟ 2. ما المنهج الذي يجب اعتماده في دراسة اللغة حتى نصل إلى نتائج علميّة موضوعيّة؟

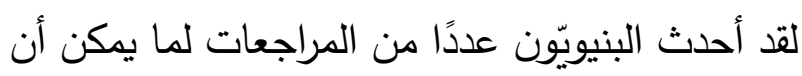
يدخل ضمن حدود العلم وما يجب أن يخرج عند، فنجد أنّ عددًا من القضايا التي كانت تدخلها الدراسة اللغويّة

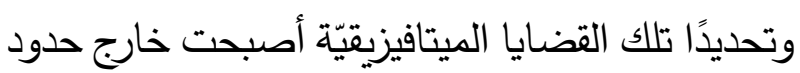
البحث اللسانيّ، فلم تعدُّ قضايا من قبيل: التفاضل بين

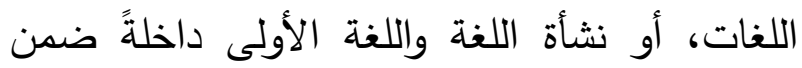
موضوع الدرس اللسانيّ، وكان الدافع لذلك الوفاءً للمنهج العلميّ وإبعاد القضايا التي يفقد اللسانيّ فيها القدرة على الوصول إلى معطيات تمكّنه من الوصول 
اللسانيّ لطبيعة العلامة اللغويّة (أو علاقة الدليل اللغويّ بمدلوله)، وقيام الرؤية البنيويّة في دراسة اللغة على مفهومي (النظام) و(القيمة). ويجعل هذا التصوّر

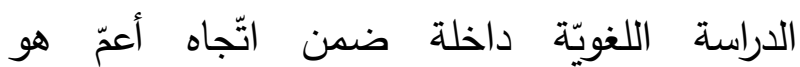

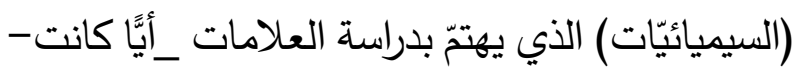
في الحياة الاجتماعيّة. ويؤول هذا التصوّر إلى أنّ اللغة خاضعة لمواضعات اعتباطيّة تحكم طرائق استعمال اللسان وأوجها المتعدّدة التي يكتسبها الفرد من محيطه، وعلى اللسانيّ إذا أراد أن يدرس اللغة تقديمُ وصف لائق واكتشاف البنية الداخليّة التي تحكم اللسان المدروس انطلاقًا من معطياته الملموسة؛ لذلك كان لـ(المتن اللغويّ أو المدوّنة اللغويّة) قداسة ومرجعيّة مهمّة عند البنيويّين. ولا يغيّر اختلاف (بلومفيلد) والسلوكيّين عامّة مع افتراض أنّ اللغة ظاهرة اجتماعيّة من كون المعرفة اللسانيّة لدى الفريقين كامنة في معطيات اللغة الخارجيّة، أو ما أسماه تثومسكي اللغة المجسَّدة(23)، إذ إنّ البنيويّة الأمريكيّة مع (بلومفيلد) احتذت علم النفس السلوكيّ الذي أسّسه (واطسون)، وكان يروم وضع علم نفس موضوعيّ يستبعد كل مظاهر الاستبطان والذاتيّة، ويريد تقسير مظاهر السلوك الإنساني بناء على المعطيات الخارجيّة بوصفها عددًا من المثيرات والاستجابات، وتبنّى (بلومفيلد) السلوكيّة ليفسر بها مظاهر السلوك اللغويّ عند الفرد المتكلّ.

ونخلص إذن إلى أنّ النموذج العلميّ البنيويّ مبنيّ
أسلفنا- كان ينظر إلى العلوم الصحيحة بوصفها النموذج الذي يجب أن يطمح علم اللسانيّات في الارتقاء إلى مصافّها بتجاوز خصوصيّة الدراسات اللغويّة التقليديّة إلى بناء علم كونيّ. ونفصل هذا بوضوح عن أمر آخر هو تصوّر البنيويّين لطبيعة اللغة، ونذكّر هنا أنّ التصوّر البنيويّ لطبيعة اللغة أحدث تحوّلًا من كونه يعدُّ اللغة إحدى الظواهر الطبيعيّة التي تسري عليها ما تسري على ظواهر الطبيعة من أنظمة وفرضيات إلى النظر إليها بوصفها ظاهرة اجتماعيّة مع التذكير بضرورة الفصل بين ما هو فرديّ (الكلام) وما هو اجتماعيّ (اللسان). (21) ويظهر هذا الموقف البنيويّ في ما ذكره إدوارد سابير عن حقيقة اللغة والمناظرة بينها وبين (E.Sapir) المشي لتبديد الوهم الذي يحيط بالتعرف على حقيقة ظاهرة اللغة، فيختصّ الطفل بمجموعة من العوامل البيولوجيّة التي تفضي به إلى المشي، وأما اللغة فتعود إلى كونه نشأ في مجتمع أكسبه تعلّم لغة ما. ويستدلّ لهذا الرأي بأن محيط الطفل مهما تغيّر فإن طريقة مشيه لن يحدث فيها تغيير ، بخلاف اللغة التي ستظل متغيّرة بتغيّر محيط الطفل الذي سينشأ فيه؛ فاللغة عنده ليست وظيفة غريزيّة، وإنما هي وظيفة ثقافيّة اكتسابيّة. (22)وانطلاقًا من هذا التصوّر الذي يعدُّ اللغة ظاهرة اجتماعيّة نجد أنّ الدراسة اللغويّة وعلم الاجتماع أصبحت بينهما صلة، وصار للدراسة اللغويّة تبعًا لهذا الافتراض -الذي يعدُّ اللغة ظاهرة اجتماعيّة-سماتها ضمن هذا الاتجاه البنيويّ، وأشهرها التصوّر 
قيمتها الداخليّة، والوظيفة التي يجب أن تضطلع بها. المراجعة التي تكون راجعة إلى عجز النظريّة عن تقديم وصف علميّ لبعض الظواهز وتفسيرها، فهو راجع إلى معاندة بعض الوقائع للنظريّة. ونحاول في هذا السياق أن نبيّن قصور الاتِّاه

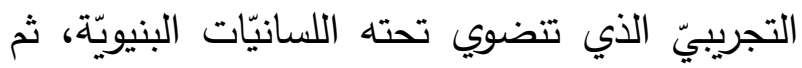
نعرض القصور الذي رآه تثومسكي في اللسانيّات البنيويّة من جهتين: نقد الجانب النظريّ في اللسانيّات البنيويّة، ثم نقد الجانب الإجرائيّ فيها.

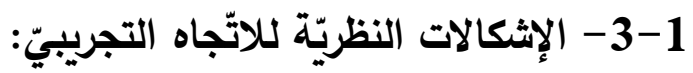
تبدو الملاحظة الأولى التي وُجّهت للتأسيس الذي يقوم عليه الاتِّاه التجريبيّ متمثّلة فيما يمكن أن نسمّيّه

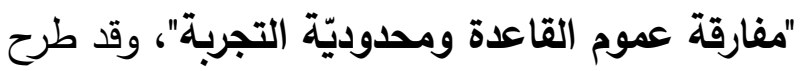

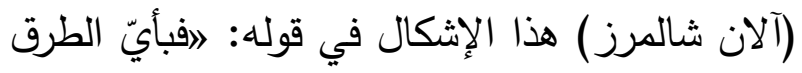
يتمّ الانتقال من المنطوقات المفردة الناتجة عن الملاحظة إلى التعابير الكلّيّة التي تثكّل المعرفة العلميّة؟ وكيف نبرّر هذه الإثباتات ذات المدى العامّ

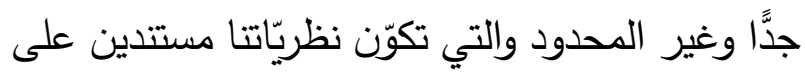
حجّة محدودة مكوّنة من عدد محدود من منطوقات

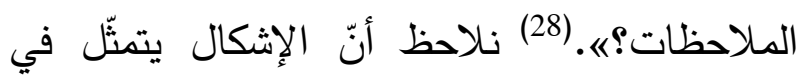

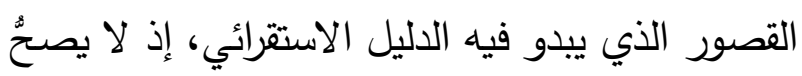
تعميم سلسلة محدودة من منطوقات الملاحظة الفرديّة

$$
\text { في صورة قانون كلّيّ. }
$$

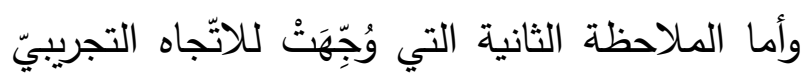

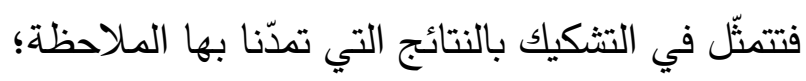

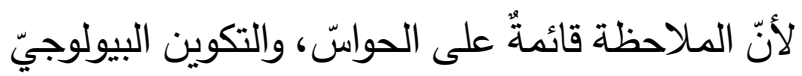

على التسليم بأنّ المعرفة اللسانيّة كامنة في معطيات

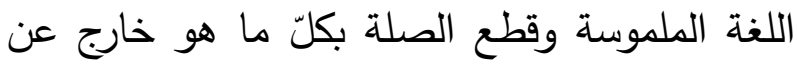

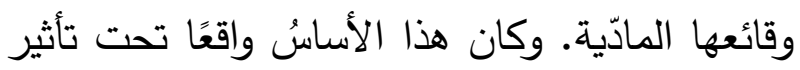
الحذر الثديد من خرم شرط (الموضوعيّة) وتحيّزات الباحث لرغباته الذاتيّة مع ضرورة الإكتفاء بالجانب الوصفي القائم على جمع المعطيات وتصنيفها؛ لأنّ

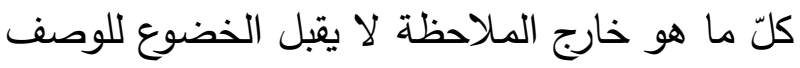

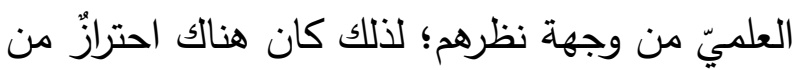
المعنى بإقصائه كما نجده في البنيويّة الأمريكيّة، أو هن الوعي بإشكاليّته ووضع الضوابط التي تقي الباحث من الوقوع في مزالقه كما نجده عند هيلمسليف. النموذج العلمي في اللسانيّات التوليديّة: (25) ارتبط اسم تشومسكي بالثورة على البنيويّة بوصفه

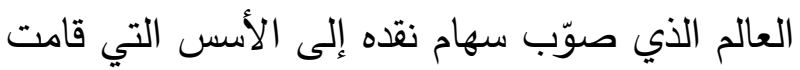

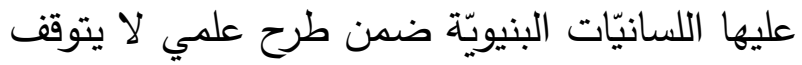
عند حدود اللسانيّات، وإنّما يحدث تغيرًاً في المرجعيّات فئي المعرفيّة التي كانت سائدة حتى خمينيّات القرن الماضي وتأسّست عليها عدد من النظريّات التي تتنمي إلى علوم مختلفة. (26) وتمثّلت الثورة المعرفيّة في اللسانيّات التوليديّة على التصوّر السائد للعلم بكونه التصوّر الذي يعتّد أنّ العمل العلميّ نشاط يقوم على جمع المعطيات وتصنيفها وربط قوانينها بالتجربة والممارسة. (27) ولا بدَّ من الإشارة إلى أنّ تطوّر النظرِّيّات العلميّة ومراجعتها تكون وفق اتِّاهين:

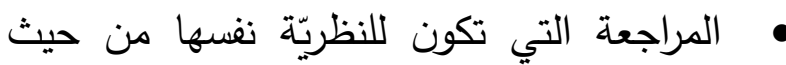


تأسيسًا على ما أشرنا إليه من نقود وُجِّهتْ إلى الاتِّاه

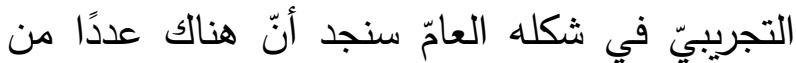
المشكلات التي واجهها اللسانيّون البنيويّون، ولا شكَّ

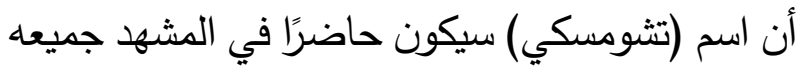
إذا نوقثت هذه المسائل؛ فهو الذي وجَّه سهام نقده للمنطلقات البنيويّة في كتابه المنشور عام 1957م بإشارته إلى السمات التي يجب أن تتوفّر في النظريّة العلميّة، إذ قال: الاوكلّ نظريّة علميّة لا بدَّ أنْ تعتمد عددًا محدودًا من الملاحظات، وتحاول تفسير الظواهر هذه، ثم التكهّن بظواهر جديدة عن طريق صياغة قواعد عامّة طبقًا لتراكيب فرضيّة كما هو الحال بالنسبة لـ(الكتلة) و (الإلكترون) في الفيزياء مثلاه(31) نجد أنّ تشومسكي في هذا النصّ يوجّه نقده المباشر للبنيويّين التوزيعيّين في نقطنين مهمّتين: •أنّ الملاحظات لا تمدُّنا وحدها بالمعرفة العلميّة؛ لعين لذلك يجب تجاوزها إلى غيرها إذا أردنا بناء نظرية علميّة، ثم ننزّل الوقائع والملاحظات التي يمدّنا بها الواقع منزلتها اللائقة بها.

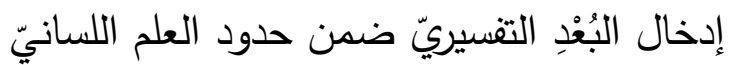
بعد أنْ كان الاتّجاه البنيويّ مكتفيًا بالوصف، فلا بدَّ

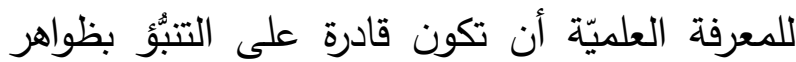
مماثلة انطلاقًا من القواعد العامّة. وقوَّض تشومسكي كذلك المرجعيّاتِ البنيويّة الأمريكيّة

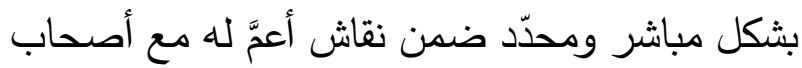
الددرسة السلوكيّة وأنصارها. وكان النقد الذي وجّهه (تشومسكي) لعالم النفس (سكينر) بعد نشر الأخير
للحواسّ وكيفيّة عملها بارتباطها بالدماغ لا يسمح بنقل

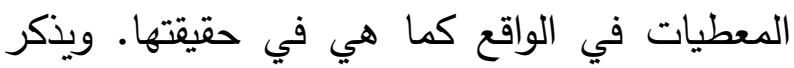
العلماء قديمًا وحديثًا للاستد لال على هذا القصور عددًا من الثواهد التي تؤكّد عدم الثقة بما تتقله الحواسّ. (29) ويؤكّد هذا أنّ معرفة المُعطى العلمي تكون دائمًا ضمن إحداثيّات نظريّة محدّدة، فالحواسّ على صدقها تمدّنا بمعطياتٍ تكيّقها خصائصُ الحواسّ وحدودُها، ونجد ذلك جليَّا في الأصوات المدركة والأصوات غير المدركة، فتوجد أصواتُ لا نسمعها؛ لأنها دون الحدّ

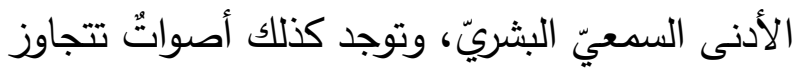
حدود طاقة الأذن البشرية، ونقيس على ذلك حاسّة الإبصار وإدراكها للألوان. وقد أصبحت علوم الإدراك أكثر تطوَّرًا فكثفت آليات الإدراك البشري، وليس هذا سياق نتوخّاه في البحث؛ فنكتفي بالإثارة إلى قصور الحواسّ بما يجعلنا غير مطمئنيّن إلى ما تمدُّنا به الملاحظة، ودحض فرضية التجريبيّين أن بناء العلم على الملاحظة يجعلنا أكثر لهر موضوعيّة؛ لأنَّ 》ما يراه الملاحظون-أي التجارب لهاه

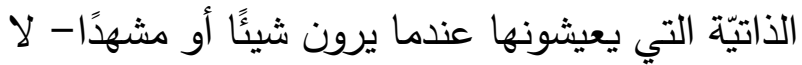
تحدّده الصور التي ترتسم فوق شبكياتهم فقط، بل تحدّده أيضًا التجربة والمعرفة والحالة العامّة للملاحظ《.(30)ويؤول هذا إلى أنّ ذات الباحث تسهح في تكوين المعرفة المبنيّة على الملاحظة والتجربة، ويعني هذا أنّ التجريبيّن واقعون فيما حاولوا أن

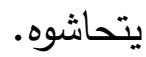

1-4-1 نقد الجوانب النظريّة في اللسانيّات البنيويّة: 
تشومسكي من هذه الملاحظة إلى القول بوجود الخاصّيّة (الإبداعيّة) لدى الإنسان. والقول بهذه الخاصيّة الفريدة لاى الإنسان يجعل فرضيّات السلوكيّين عاجزة عن تقسير سلوكه اللغويّ. فقد أصبحت هذه الخاصيّة (الإبداعيّة) هي الفرضيّة القادرة على تفسير قدرة الإنسان على إنتاج ما لا تتاهي

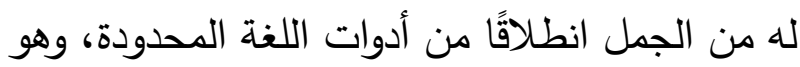
ما لا يتوفّر للحيوان أو الآلة، فهما لا يستطيعان

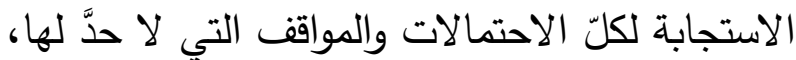
ولا يتصرّفان إلا بحسب المدخلات التي تحدّد استجابتها للمثيرات المحدّدة؛ لذلك يعدُّ (فردريك ماكس لهن مولر ) اللغةَ حدود مملكةِ الإنسان التي لن تجرؤ بهيمة

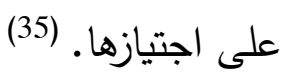
ويؤول هذا الافتراض إلى أنّ اللغة عضو بيولئي

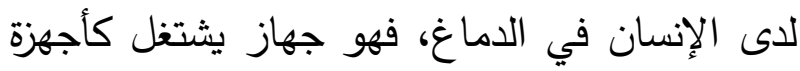
الإنسان الأخرى كالإبصار ونحوه. وتكون اللسانيّات بهذا المفهوم ذات إسهام مهمّ في دراسة الطبيعة البشريّة وفههها؛ فمتى تقدّمنا في معرفة اللغة تقدّمنا في معرفة الطبيعة البشريّة، والعكس كذلك. 1-5- نقد الجوانب الإجرائيّة في اللسانيّات البنيويّة: يمكن الاعتقاد بأنَّ لدى تشومسكي نظرة للسانيّات

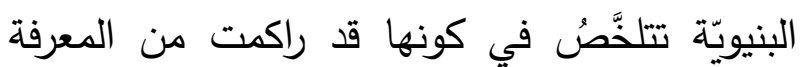
اللسانيّة ما أنتجت به علمًا مفيدًا وأضحى الأفق اللسانيّ بعد ذلك يعاني انسدادًا يجب أن تتجاوزه اللسانيّات من الاقتصار على الملاحظة والجانب الوصفيّ إلى الاهتمام بالقضايا التي يمكن أن يحقّق
في نهاية خمسينيّات القرن العشرين كتابه (السلوك اللغويّ) الذي يتّخذ المذهب السلوكيّ أساسًا له في التفسير أحدَ النقود التي قوَضضت المنطلقات السلوكيّة التي كان يستتد عليها اللسانيّون الأمريكيّون أمثال

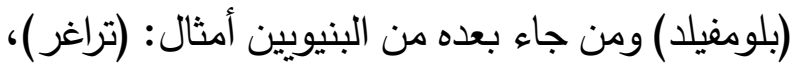
و (بلوتش)، و (هوكيت)، و (نيدا)، و(هاريس) وغيرهم، وكانت قضيّة (اكتساب اللغة) هي المدخل التي انطلق منها تشومسكي لمراجعة أقوال السلوكيّين وتجاوزها.

فقد استند تشومسكي في نقده للسلوكييّن بقصور منطلقاتهم القائمة على ثنائية (المثير والاستجابة) على لى قدرة الطفل ذي السنوات الثلاث، أو الأربع على تأويل عدد كبير جدًا من الجمل التي ليس له تجربة سابقة معها، وقدرته كذلك على إنتاج عدد غير محدود من الجمل الجديدة التي لم تكوّنها لديه التجربة. ثم ينطلق تشومسكي كذلك من تمييز مهمّ يقيمه -تبعًا لـ(ديكارت)- بين الإنسان من جهة والحيوان والآلة من سن جهة أخرى(33)؛ فلئن بدا التفسير السلوكيّ القائم على دنى فرضيّة (المثير والاستجابة) ناجعًا في تفسير سلوك بعض الحيوانات بالتنبُّؤ بسلوكها انطلاقًا من مثيرات معيّنة في حالات محدّدة فإنّ هذه الفرضيّة لا يمكنها التنبؤُ بالسلوك اللغويّ الإنسانيّ انطلاقًا ممّا تمليه

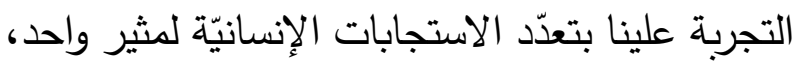
وتكون النظريّة بذلك فارغة لا معنى لها. (34) وتقوم هذه التفرقة التشومسكيّة بين الإنسان والحيوان والآلة على الفارق البيولوجيّ بينهما؛ فينطلق 
لتتفيذ برنامج النحو التوليديّ أنّ كثيرًا من الخصائص اللغويّة الأساسيّة لم تلاحظ حتى في اللغات التي دُرست بكثافة، وأنّ أكثر الأنحاء التقليديّة تفصيلًا

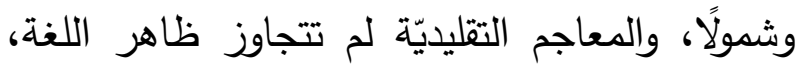
وظلّت خصائص اللغة الأساسيّة مفترضة طوال تلك لك الكائ الفترة لكنّها لم تدرك ولم يعبَّر عنها. وهذا ملائم جدًا إن كان الهدف من الدراسة مساعدة الناس على تعلّم لغة ثانية، أو اكتثاف المعنى المتواضَع عليه للكلمات أو الطريقة التي تُطق بها أو تحصيل فكرة عامّة عن الكيفيّة التي تختلف بها اللغات بعضها عن بعض. أمّا إن كان الهدف فهم الملكة اللغويّة والحالات التي لهي لهني

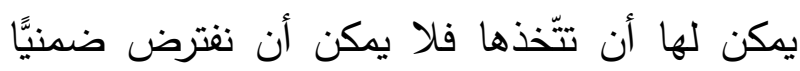
(ذكاء القارئ). بل إنَّ هذا هو موضوع الدراسة بدلًا لهن لهن من ذلكه."(39) وأصبح الاهتمام متوجِهَا في البحث اللسانيّ التوليديّ إلى ما يحقّق وحدة اللغات البشرية بعد أن كان البحث اللسانيّ قبلها متوجِّها إلى خصائص التص اللغات المختلفة تبعًا لما تبدو عليه في ظاهرها من اختلافات في خصائصها الصوتيّة والصرفيّة والتركيبيّة والمعجميّة. وكان الدافع للاهتمام بالمظهر الكلّي في اللغات المختلفة ما أملته المنطلقات التوليديّة بعد التنكير في لهني (مشكل أفلاطون)(40) أنّ اللغة جهازٌ بيولوجيّ لدى لـاني

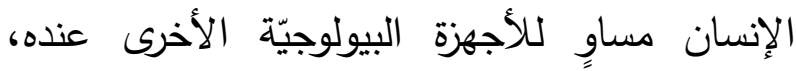
ويكون نموّه قريبَ الشبه بنموّ الأعضاء بشكل عامّة.

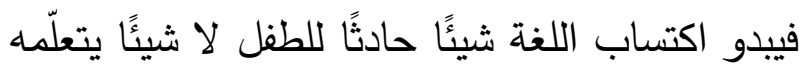
دون إنكار لأهيّة البيئة اللغويّة وأثرها.
فيها علم اللسانيّات تقدّمًا في معرفة طبيعة اللغة وفهم آليات اكتسابها واستخدامها. وقد وجَّه تشومسكي عام 1957م في كتابه (البنى التركيبيّة) نقدًا للتحليل بواسطة المكوّنات المباشرة ببيانه القصور الذي يعتري هذا النموذج في تحليل بعض الجمل. ويمثّل الإثكال في نموذج المكوّنات المباشرة بعدم قدرته على المناظرة بين الترتيب الخطّيّ ليّي للجملة والترتيب البنيويّ؛ لأنّ التحليل بالمكوّنات المباشرة معنيٌّ بالترتيب الخطّي فقط في تحليل الجمل دون أن يكون هذا التحليل موافقًا للترتيب البنيويّ أو البنية العميقة للجملة فيقع هذا النوع من التحليل في إثكالات من قبيل: عدم قدرته على رفع اللبس في الجملة؛ لذلك أدخل تشومسكي التحويلات لتكون قادرة على التوفيق بين الترتيب الخطيّ (البنية السطحيّة) والترتيب البنيويّ (البنية العميقة). (37) 1-6-1 موضوع البحث اللسانيّ في اللسانيّات

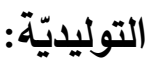
أعادت اللسانيّات التوليديّة الاعتبار إلى كثير من التقاليد الفلسفيّة واللغويّة القديمة بجعل موضوعاتها قضايا يجب أن يهتمّ بها البحث المعاصر بعد أن كانت مقصاة من البحث إلى حدود خمسينيّات القرن العشرين.(38) وفي السياق نفسه أبدت اللسانيّات التوليديّة نقدًا لما كان موضوعًا للبحث اللسانيّ وما أثمرته من نتائج لتحدّد من خلاله الموضوع الذي يجب أن تهنمّ به الدراسة اللسانيّة في هذا السياق، قال تشومسكي: اوسرعان ما كثفت المحاولات المبكرة 
الخاصيّة (الإبداعيّة) ل لديه. فأصبحت اللسانيّات التوليديّة تروم بناء نحو كلّي يحاكي العلميّات الذهنيّة التي تحدث في الدماغ لإنتاج اللغة وتأويلها. وتكون اللغات البشريّة المختلفة بهذا المفهوم معطياتٍ تعين في اكتثاف هذا النحو الكلّي وتقويمه بعد أن كانت اللسانيّات البنيويّة تبني أنحاءها انطلاقًا سبشكل

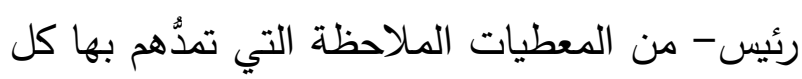
لغة بشريّة، فوقع تحوّل أو ثورة معرفيّة من الاعتقاد بأنّ المعرفة اللسانيّة كامنة في معطيات اللغة ووقائعها الملموسة إلى إعطاء هذه المعطيات منزلة ثانويّة في النموذج العلميّ التوليديّ، ويمكن أن يبيّن هذه التحوّل

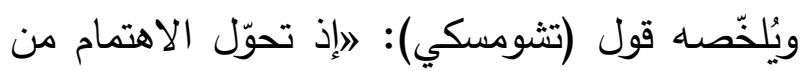
ملاحظة السلوك والنتائج المحصّلة منه (كالنصوص) إلى الآلّيّات الداخليّة التي تدخل في التفكير والفعل.

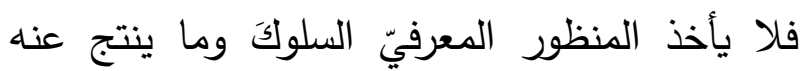
موضوعًا للدرس، بل مادّة أوّليّة يمكن أن تقدّم لنا أدلة على آليّات الذهن الداخليّة والطرق التي تنفِّن بها هذهن

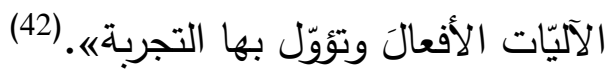

النموذج العلميّ في اللسانيّات الوظيفيّة: (43) نحدُ الاهتمام في هذا السياق بالنحو الوظيفيّ الذي في قدّمه (سيمون ديك) عام 1978م ثم احتذاه في الدراسات العربيّة أحمد المتوكّل وأصبح مشروعه الذي الذي كتب فيه مجموعة من المؤلّفات والأبحاث، وقد اخترنا هذا الحدّ لأسباب، أهمها: • أنّه اختيار يتلاءم وطبيعة الموضوع الذي نهتمّ به الهبه

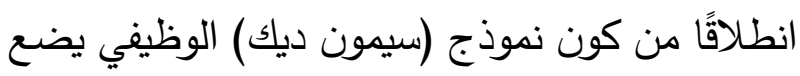

ويضع تشومسكي إطارًا يحدّد الآلَّة التي تكوّن اللغة وتحدّد العلاقة بين الجانب الفطريّ والجانب المكتسب، ويتمثّل ذلك بأنّ المسار العامّ لتكوّن اللغة والسمات

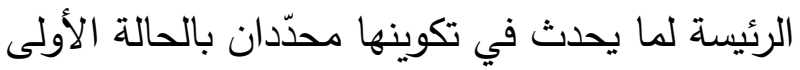
مسبقًا للغة التي يشترك فيها الناس مهما اختلفت أعراقهم ولغاتهم وهو الممثّل للجانب (الكلّي) من اللغة. فيجب أن تكون اللغات في خصائصها الرئيسة مفصّلة من قماش واحد -جسب تعبير (تشومسكي)-، ولتحقّق النظريّة اللسانيّة هذه الغاية يجب أن تتوخّى

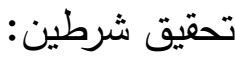

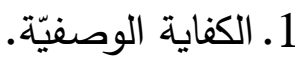

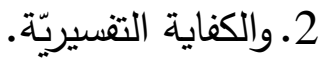
ويُعدُّ هذا التوخّي تجاوزًا للسانيّات البنيويّة التي كانت مكتفية بالكفاية الوصفيّة وحدها في حين أن التوليديّة ألحّت على ضرورة الاهتمام بالكفاية التفسيريّة؛ فيجب أن يحقّق نحو لغة ما هذا الشرط ببيان كيفيّة اشتقاق

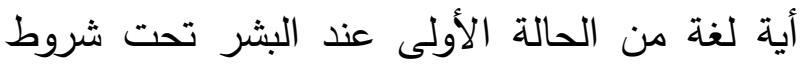
الحدود التي تفرضها التجربة؛ لتوفّر النظريّة تفسيرًا لخصائص اللغات في مستوى أعمق. (41) ونجد أنّ اللسانيّات بهذا التصوّر التشومسكيّ تخلّت عمّا كان سائدًا في اللسانيّات البنيويّة من التسليم بتعدّد

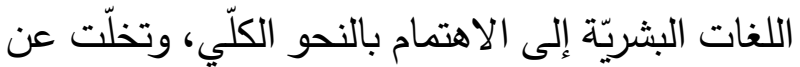
مرجعيّة الواقع وملاحظة المعطيات لصالح (سليقة المتكلّم أو المستمع المثاليّ أو الفطريّّ) انطلاقًا -ممّا

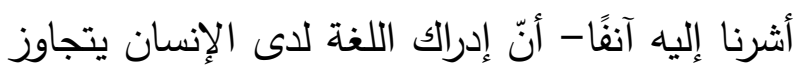

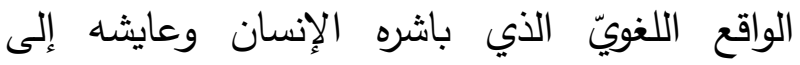


لقد كانت الاتِّاهات اللسانيّة بعد خمسينيّات القرن الماضي كوظيفيّة كانت أو غير وظيفيّة- تتقاسم غاية واحدة تتمثّل في استكثاف خصائص النحو الكلّي، وتُسلّم بأنّ معطيات الألسنة البشريّة المختلفة مادّةٌ يُتوسّل بها للوصول إلى هذه الغاية بوصفها صورة جزئيّة لما حدث من عمليّات ذهنيّة تخلق اللغة وتكوّنها. وتمثّل معرفة (المتكلّم/السامع) المثاليّ المشترك والغاية بين هذه الاتّجاهات اللسانيّة المختلفة. ولكنّ تحقيق هذه الغاية والتعرّف على طبيعة هذه

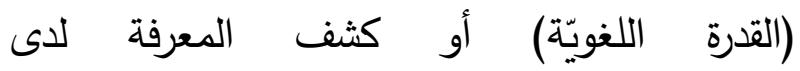
(المتكلّم/السامع) المثاليّ تختلف بين الوظيفيّين وغيرهم، وهذا هو الاختلاف بين الاتِّاهين الوظيفيّ والتوليديّ في تصوّر الجهاز النظريّ الموصل للغاية المتحدة بينهما. كان التوليديّون يعتقدون أنّ معرفة (القدرة اللغويّة) لدى (المتكلّم/السامع) المثالي تتمثّل في القواعد الصوتيّة، والقواعد الصرفيّة، والقواعد التركيبيّة، والقواعد الدلاليّة (الدلالة المرتبطة بالدلالة اللغويّة الصرف)، وأمّا الجانب التداوليّ، والجانب الوظيفيّ فيُعدَّان داخلين في (الإنجاز اللغوي) أكثر من كونهما داخلين في (القدرة اللغويّة)، وهو (أي الإنجاز اللغويّ) عند التوليديّين جانبّ في اللغة غيرُ داخل في إطارهم النظريّ إلى حين وضع نظريّة للإنجاز توازي النظريّة المفسّرة لـ(القدرة اللغويّة). (46) ويمكن أن نعدَّ ما كتبه (جون سيرل) عام 1973م هو بداية النقد الذي وُجِّه لتشومسكي في استبعاده الجانب
ضمن إطاره النظريّ بعض المنطلقات اللسانيّة السابقة موضع المراجعة والنقد، وسيأتي بيان ذلك. أنّه اتِّاه أصبح لله حضور في ساحة البحث اللسانيّ العربيّ بما أنجزه أحمد المتوكّل من تطبيق للنظريّة على ظواهر في اللغة العربيّة، وتجاوز التطبيق إلى محاولة الإضـافة النظريّة انطلاقًا ممّا اكتسبه من معطيات اللسان العربيّ الذي اشتغل عليه في الجانب التطبيقيّ، إضافة إلى استيعاب أحمد المتوكّل في أعماله لكثير ممّا في الاتّجاه الوظيفيّ من نماذج صوريّة متنوّعة. ونقدّم -قبل إظهار التحوّل في النموذج العلميّ للسانيّات الوظيفيّة- الخصائص التي تتقاسمها النظريّات اللسانيّة الوظيفيّة وغير الوظيفيّة، وتتمثّل في النقاط الآتية: - مي 1. اللسان الطبيعيّ هو الموضوع الذي تشتغل فيه هذه النظريّات وظيفيّة كانت أو غير وظيفيّة. 2.ضرورة مجاوزة الوصف إلى التفسير، فهذه النظريّات جميعها تُسلّم بأنّ الدراسة اللسانيّة يجب أن تكون ذات كفاية وصفيّة وكفاية تفسيريّة. 3.تجعل هذه النظريّات استكثاف خصائص النحو الكلّي للألسنة البشريّة غايةً لها، ثم تغريع الأنحاء الخاصّة عنه لوصف كلّ لسان وحده. 4.تحاول النماذج الصوريّة التي تفترضها هذه النظريّات وصف (القدرة اللغويّة) وتقسيرها لا (الإنجاز الفرديّ). (44) النموذج العلميّ في اللسانيّات الوظيفيّة: (45) 
بيّنٌ في بنية اللغة بمجيء التركيب في صورة توائم الوظيفة التواصليّة للغة. فلئن اهتمّ الوظيفيّون في مراحل متقدّمة من البحث

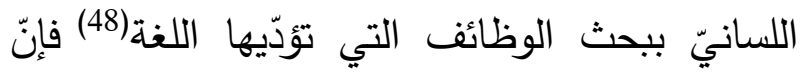
الاهتمام الوظيفيّ منذ عام 1978م أصبح يضع نصب عينيه الوظيفة الأساس للغة وهي أنّ اللغة تتيح لمستعمليها التواصل بينهم. وقد اجتهد الوظيفيون في حثد عدد من المعطيات اللغويّة من الألسنة المختلفة التي تدعم فرضيّتهم بالعلاقة الوثيقة بين البنية والوظيفة بالتدليل على اختلاف البنية تبعًا للاختلاف لئل

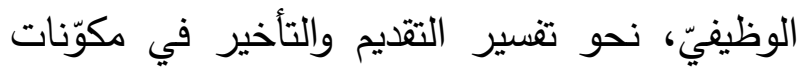

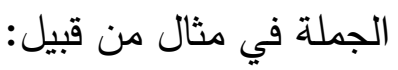

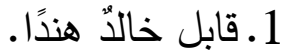

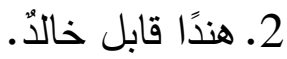
فيرى الوظيفيّون أنّ هذا التقديم والتأخير راجع إلى أنّ تقدّم المفعول تحكمه الوظيفة التداوليّة (بؤرة المقابلة)

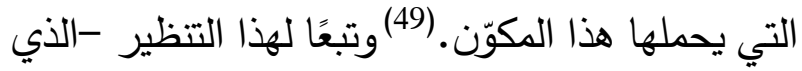
يرى أنّ البنية تكون تابعة للوظيفة- نجد أنّ النموذج العلميّ الأمثل لتفسير اللغة من وجهة نظر الوظيفيّين هو المصوغ على أساس تمثيل الخصائص الدلاليّة والتداوليّة في مستوى (البنية العميقة) وتمثيل الخصائص البنيويّة في مستوى متأخّر من مستويات الاثتثقاق المتمثّل في (البنية المكوّنيّة)، وأن يقع ربط بين البنيتين (أو المستويين) عن طريق نسق من القواعد تتخّ المعطيات في البنية العميقة عن لئن

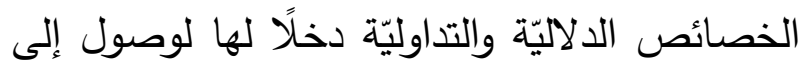

الوظيفيّ للغة، إذ قال: 》إنّ معظم المعلقين المتعاطفين مع نظرية (تشومسكي) قد انبهروا بالنتائج التي تََّّ التوصّل إليها في علم التركيب إلى الحدّ الذي لم يلاحظوا معه كم يتعارض قسم كبير من النظرية مع المفترضات الثائعة المتعلّقة باللغة. فاللغة بالنسبة للحسّ العامّ مكيّة لأداء وظيفة الاتصّال. كالقلب تقريبًا المكيَّف هو أيضًا لأداء وظيفة ضحنّ الدم. ومن لهن الممكن في الحالتين دراسة البنية بصورة مستقلّة عن الوظيفة، ولكن من الخطأ وغير المجدي القيام بذلك لكانك

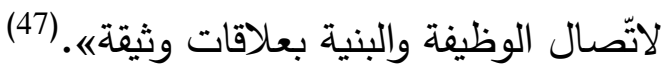
ويني (سيرل) حجّته بأنّ تاريخ تطوّر اللغة الإنسانيّة

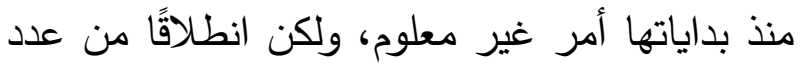
من الملاحظات يعتقد أنّ من الملائم افتراض التأثير الحاصل بين بنيتها ووظيفتها في الاتّصال في رسم شكل للغة الإنسانيّة. ويواصل (سيرل) استدلاله ممّا شاع في كتب التوليديّين حين يريدون التمثيل للالتباس الذي يسود البنية السطحيّة من قبيل: • نقد تشومسكي نقد لاذع.

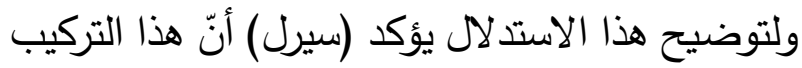

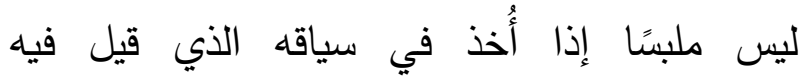
واستحضرت معه ملابسات القول بين أطرافه، فلا يحدث لدى المخاطب لبس في فهم المراد منها بين

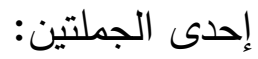
• نقد تشومسكي لأحدهم نقد لاذع.

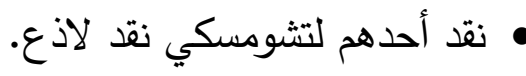

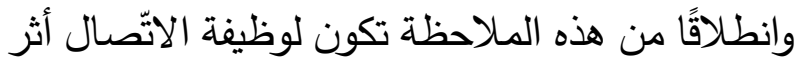


في الذهن؛ ونظرًا للعائق الأخلاقيّ -كما يسمّيه تشومسكي- الذي يمنع من الكثف الاختباريّ كمّا يجري في الذهن ظلَّ اللسانيّون يبحثون عن النموذج الأمثل في وصف اللغة وتقسيرها. الخاتمة

نختم الدراسة بأهمّ النتائج التي وصلنا إليها، ونجملها في الفقرات الآتية: ه أنّ الوعي بحقيقة المعرفة العلميّة وآلّيّات بنائها وتطوّرها يمنح الباحث التقدير الموضوعيّ للعلم، ويجعله مثمَنًا لتطوّره وآليّات اشتغاله. • كانت اللسانيات في المرحلة البنيوية تحمل سمات مختلفة ولاسيّما إذا نظرنا إليها في ضوء المدرستين؛

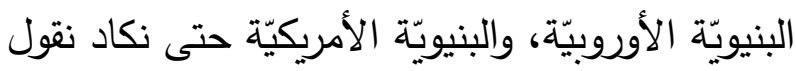
إنّ في البنيويّة نماذج علميّة متعدّدة، ويمكن أنْ نجمل لالنه التحوّل في النموذج العلميّ البنيويّ بكونه عدَّلَ ما كان سائًاًا في النموذج العلميّ قبله مع اللسانيّات التاريخيّة التي عدَّت اللغة ظاهرة طبيعيّة تناظر الحيوانات، والنباتات، وغيرها من ظواهر الطبيعة؛ فافترضوا أنها -أي اللغة- يجري عليها ما يجري على الظواهير مناهر الطبيعيّة. ولذلك تكون اللغة - -عند التاريخيّينخاضعة لقانون التطوّر، فهي ظاهرة تتثكّل وفق قوانين محدّدة، وتخضع للتطوّر ثم الانقراض التدريجيّ. فجاءت اللسانيّات البنيويّة وعدَّت اللغة ظاهرة اجتماعيّة مع ضرورة الفصل بين ما هو فرديّ (الكلام) وما هو اجتماعيّ (اللسان). فحقيقة اللغة مهنة عندهم مختلفة عن غيرها من الظواهر البيولوجيّة؛ إذ إذان
رصد وتفسير ذي كفاية متحقّقة لتمثيل العلاقة بين البنية والوظيفة (أو الخصائص البنيويّة بالخصائص الدلاليّة والتداوليّة). (50) وقد أصبح موضوع البحث اللسانيّ مع الوظيفيّين انطلاقًًا من تصوّراتهم السالفة هو (القدرة التواصليّة) في مقابل (القدرة اللغويّة) عند التوليديّين. ويعدُّ هذا قارقًا جوهريًّا بين الاتّجاهين، إذ إنّ (القدرة اللغويّة) عند التوليديّين تقتضي أنّ لدى (المتكلّم/السامع) المثاليّ قدرتين؛ قدرة نحويّة، وقدرة تداوليّة، ويقصر الاهتمام عندهم على القدرة النحويّة وحدها. وأمّا القدرة اللغويّة عند الوظيفيّين فهي قدرة واحدة تجمع بين النحو والتداول، وسمّوها (القدرة التواصليّة) التي تتكوّن

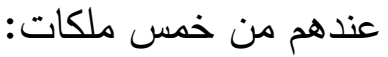

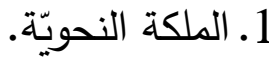
2. - 2 - والملكة المنطقيّة. 3. والملكة المعرفيّة.

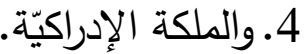
5. 5. 5المكة الاجتماعيّة. (51) نلحظ أنّ النموذج العلميّ اللسانيّ مع الوظيفيّين أدخل الجوانب التداوليّة داخل النموذج التفسيريّ للألسنة

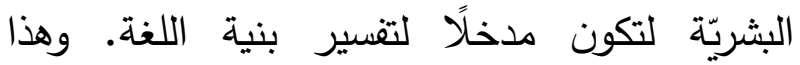
الاختلاف بين الاتجّاهين (التوليديّ، والوظيفيّ) اختلاف في مستوى الفرضيّات الكاشفة عن اشتغال جهاز اللغة البيولوجيّ لدى الإنسان؛ لأنّهما يشتركان في فرضيّات واحدة عن مصدر اللغة -كما سبق-، ويتوخّيان بناء نموذج تفسيريّ يشابه نظام اشتغال اللغة 
فقد تخلَّت اللسانيّات التوليديّة بهذا التصوّر التشومسكيّ عمّا كان سائدًا في اللسانيّات البنيويّة من لتهن التسليم بتعدّد اللغات البشريّة إلى الاهتمام بالنحو الكلّي، وتخلّت عن مرجعيّة الواقع وملاحظة المعطيات لصالح (سليقة المتكلّم أو المستمع المثاليّ أو الفطريّّ)

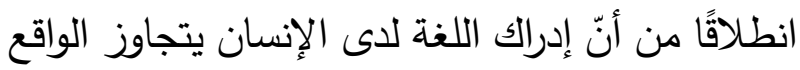
اللغويّ الذي باشره الإنسان وعايشه إلى الخاصيّة

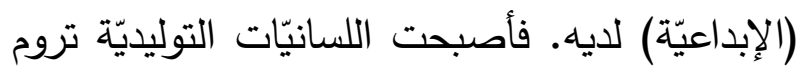

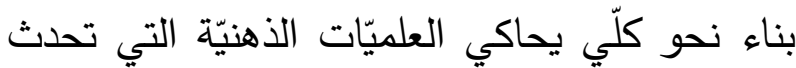

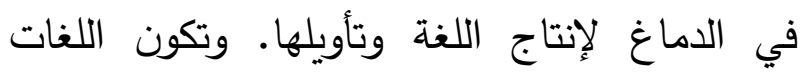
البشريّة المختلفة بهذا المفهوم معطياتٍ تعين في اكتثاف هذا النحو الكلّي وتقويمه بعد أن كانت اللسانيّات البنيويّة تبني أنحاءها انطلاقًا - سبشكل

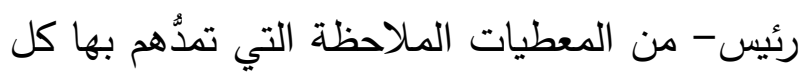
لغة بشريّة، فوقع تحوّل أو ثورة معرفيّة من الاعتقاد بأنّ المعرفة اللسانيّة كامنة في معطيات اللغة ووقائعها الملموسة إلى إعطاء هذه المعطيات منزلة ثانويّة في النموذج العلميّ التوليديّ. •تقتسم اللسانيات الوظيفيّة مع اللسانيّات التوليديّة غاية واحدة تتمثّل في استكثاف خصائص النحو الكلّي، وتُسلّم بأنّ معطيات الألسنة البشريّة المختلفة مادّةُ يُتُوسّل بها للوصول إلى هذه الغاية بوصفها صورة جزئيّة لما حدث من عمليّات ذهنيّة تخلق اللغة

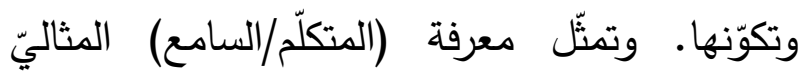
المشترك والغاية بين هذه الاتّجاهات اللسانيّة المختلفة. ويقع الاختلاف بين الاتّجاهين في تحقيق هذه الغاية
إنّ الطفل يختصُّ بمجموعة من العوامل البيولوجيّة التي تفضي به إلى المشي، وأما اللغة فتعود إلى كونه

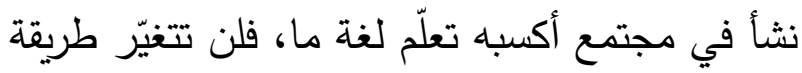
مشي الطفل مهما تغيّر محيطه، بخلاف اللغة التي ستظل متغيّرة بتغيّر محيط الطفل الذي سينشأ فيه؛ فاللغة عندهم ليست وظيفة غريزيّة، وإنما هي وظيفة ثقافيّة اكتسابيّة. • أحدثت اللسانيّات التوليديّة ثورة معرفيّة في تصوّر المعرفة العلميّة بالانقلاب على التصوّر الذي يعتقد أنّ لهن

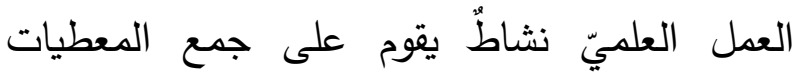
وتصنيفها وربط قوانينها بالتجربة والممارسة، وذلك لك حين وجَّةَ تشومسكي نقده المباشر للبنيويّين في نقطتين

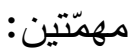
1. أنّ الملاحظات لا تمدُّنا وحدها بالمعرفة العلميّة؛ لذلك يجب تجاوزها إلى غيرها إذا أردنا بناء نظرية علميّة، ثم ننزّل الوقائع والملاحظات التي يمدّنا بها الواقع منزلتها اللائقة بها. 2. إدخال البُعْدِ التفسيريّ ضمن حدود العلم اللسانيّ بعد أنْ كان الاتّجاه البنيويّ مكتفيًا بالوصف، فلا بدَّ للمعرفة العلميّة أن تكون قادرة على التنبُُّ بظواهر مماثلة انطلاقًا من القواعد العامّة. وأصبح الاهتمام متوجِهًا في البحث اللسانيّ التوليديّ إلى ما يحقّق وحدة اللغات البشرية بعد أن كان البحث اللسانيّ قبلها متوجِهِا إلى خصائص اللغات المختلفة تبعًا لما تبدو عليه في ظاهرها من اختلافات في خصائصها الصوتيّة والصرفيّة والتركيبيّة والمعجميّة. 
والوظيفيّ) في مستوى الفرضيّات الكاشفة عن اشتغال جهاز اللغة البيولوجيّ لدى الإنسان؛ لأنّهما يشتركان في فرضيّات واحدة عن مصدر اللغة -كما سبق-، ويتوخيّان بناء نموذج تفسيريّ يثابه نظام اشتغال اللغة في الذهن؛ ونظرًا للعائق الأخلاقيّ -كما يسمّيه تشومسكي- الذي يمنع من الكثف الاختباريّ كمّا يجري في الذهن ظلَّ اللسانيّون يبحثون عن النموذج الأمثل في وصف اللغة وتقسيرها. الهوامش ولش

(1) انظر : يوسف تيبس، التصوّرات العلميّة للعالم: قضايا واتِجاهات في فلسفة العلم المعاصر ، ص22-

(2) نحيل في هذا المصطلح العلمي إلى توماس كون في كتابه (بنية الثورات العلميّة) ونشير إلى تعدّد ترجماته، من ذلك: "النموذج العلمي"، و"النموذج الإرشادي"، ومن المترجمين من اختار تعريبه فاستعمل "برادايغم"، ونشير إليه هنا رغم غرابته لالتزامنا بالإشارة إلى تعدّد مقابلات المصطلح العربيّة. (3) توماس كون، بنية الثورات العلميّة، ترجمة شوقي جلال، ص (ل151. (4) انظر : محمد الأوراغي، الوسائط اللغويّة: أفول

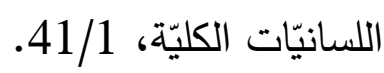

(5) انظر: مصطفى غلفان، اللسانيّات العربيّة الحديثة: دراسات نقديّة في المصادر والأسس النظريّة والمنهجيّة، ص116-118. (6) انظر : نعمان بوقرّة، الدراسات اللسانيّة في المملكة
والتعرّف على طبيعة هذه (القدرة اللغويّة) وكشف المعرفة لدى (المتكلّم/السامع) المثاليّ. وقد أصبح النموذج العلميّ الوظيفيّ متأسِّسًا على أنّ البنية تابعة للوظيفة، ليكون النموذج العلميّ الأمثل لتفسير اللغة من وجهة نظر الوظيفيّين هو المصوغ على أساس تمثيل الخصائص الدلاليّة والتداوليّة في مستوى (البنية العميقة) وتمثيل الخصائص البنيويّة في مستوى متأخّر من مستويات الاشتقاق المتمثّل في (البنية المكوّنيّة)، وأن يقع ربط بين البنيتين (أوين المستوين) عن طريق نسق من القواعد تتخذ المعطيات في البنية العميقة عن الخصائص الدلاليّة والتداوليّة دخلًا لها لوصول إلى رصد وتفسير ذي كفاية متحقّة لتمثيل العلاقة بين البنية والوظيفة (أو الخصائص البنيويّة بالخصائص الدلاليّة والتذاوليّة). فقد أصبح موضوع البحث اللسانيّ مع الوظيفيّين هو (القدرة التواصليّة) في مقابل (القدرة اللغويّة) عند التوليديّين. ويعدُّ هذا قارقًا جوهريَّا بين الاتِّاهين، إذ إنّ (القدرة اللغويّة) عند التوليديّين تقتضي أنّ لدى (المتكلّم/السامع) المثاليّ قدرتين؛ قدرة نحويّة، وقدرة تداوليّة، ويقصر الاهتمام عندهم على القدرة النحويّة وحدها. وأمّا القدرة اللغويّة عند الوظيفيّين فهي قدرة واحدة تجمع بين النحو والتداول، وسمّوها (القدرة التواصليّة). فنلحظ أنّ النموذج العلميّ اللسانيّ مع الوظيفيّين أدخل الجوانب التداوليّة داخل النموذج التفسيريّ للألسنة البشريّة لتكون مدخلًا لتفسير بنية اللغة. وهذا اختلافُ بين الاتّجاهين (التوليديّ، 
والتطوّر ، 23. ومحمد العمري، الأسس الإبستمولوجيّة

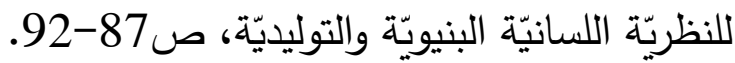
(15) فردينان دي وسوسير، دروس في الألسنيّة العامّة، ترجمة: صالح القرمادي وزميليه، ص347. (16) انظر : آلان شالمرز، نظريات العلم، ص16، ترجمة: الحسين سحبان وفؤاد الصفا. (17) محمد العمري، الأسس الإبستمولوجيّة للنظريّة اللسانيّة البنيويّة والتوليديّة، صع5-86-8 (18) محمد العمري، الأسس الإبستمولوجيّة للنظريّة اللسانيّة البنيويّة والتوليديّة، ص10 120. (19) دي سوسير ، دروس في الألسنيّة العامّة، ترجمة صالح القرمادي وزميليه، ص24. (20) انظر : مصطفى غلفان، اللسانيّات البنيويّة: منهجيّات واتجاهات، ص17. (21) انظر : دي سوسير ، دروس في الألسنيّة العامّة، ترجمة صالح القرمادي وزميليه، ص29 وما بعدها.

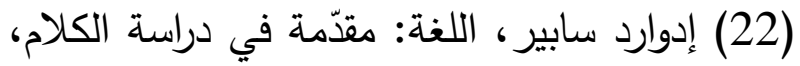
ص15-16، ترجمة: المنصف عاشور . (23) انظر : تشومسكي، المعرفة اللغويّة: طبيعتها وأصولها واستخدامها، ترجمة: محمد فتيح، ص83. (24) انظر : مصطفى غلفان، اللسانيّات البنيويّة: منهجيّات واتّجاهات، صنات381-382. (25) نذكّر بأنّ اللسانيّات التوليديّة مرَّت بعدد من التطوّرات منذ انطلاقها عام 1957م بصدور كتاب تشومسكي (البنى التركيبيّة)، وليس من غايات هذا البحث استقصاء هذه التحوّلات أو رصدها، ولكن
العربيّة السعوديّة: دراسة وصفيّة تأصيليّة في ضوء التلقّي العربيّ للمناهج اللسانيّة الحديثة، صنيه (7) انظر : برتراند راسل، النظرة العلميّة، ترجمة:

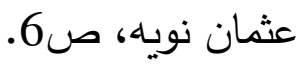

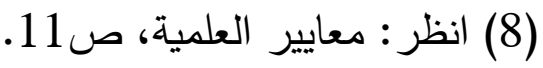
(9) انظر: السيّّ نفاديّ، التقدّم العلميّ ومشكلاته،

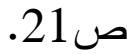
(10) انظر : يمنى الخولي، فلسفة العلم في القرن

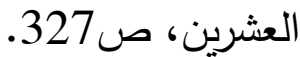

(11) انظر : السيّّ نفاديّ، التقدّم العلميّ ومشكلاته، ص12-32. وتوماس كون، بنية الثورات العلميّة، ترجمة: شوقي جلال، ص205-211. ومنى الخولي، مشكلة العلوم الإنسانية: تقنينها وإمكانية حلها،

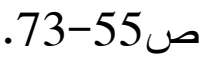
(12) انظر : آلان شالمرز ، نظريات العلم، ص157.158 (13) نعفي أنفنا في هذا السياق عن التمكك بالتفرقة

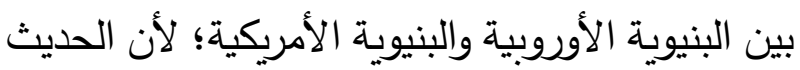
عن البنيوية في تصورها العام لكفهوم الدراسة العلمية

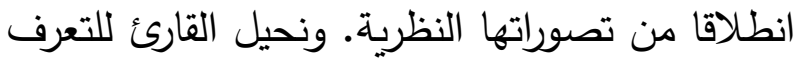
على أوجه الاتفاق والاختلاف بين البنيويتين إلى :

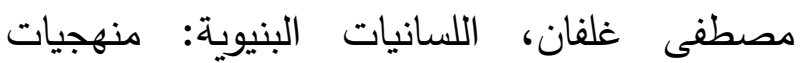
واتجاهات، ص67 وما بعدها.

(14) انظر : فردينان دي سوسير ، دروس في الألسنية

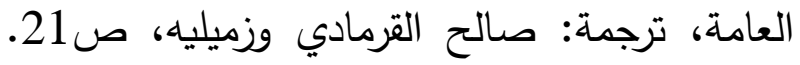
وجفري سامسون، مدارس اللسانيات: التسابق 
لن يعيشا بالضرورة تجارب بصريّة متماثلة حتى ولو كانت الصور الواقعة على شبكتي كلٍ منهما متماثلتين بالقوّة؛ فالملاحظان لا يريان -بمعنى ما- الثيء نفسه

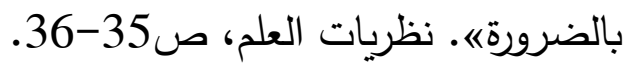
(30) آلان شالمرز، نظريات العلم، ترجمة: الحسين سحبان وفؤاد الصفا، ص37. (31) تشومسكي، البنى النحويّة، ترجمة: يؤيل يوسف ولف ولن

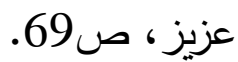
(32) الاختلاف الرئيس في هذا السياق أنّ الأطفال -من وجهة النظر التشومسكيّة- يكتسبون اللغة ولا يتعلَّمونها انطلاقًا من المحيط الذي يعيشون فيه-كما كان يرى السلوكيّون-، يقول تشومسكي: الوتقوم اللغة

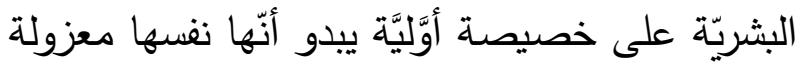

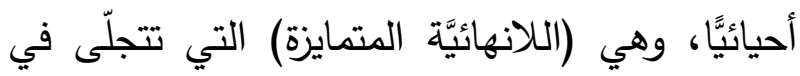
أنقى أشكالها في الأعداد الطبيعيّة، أي: 1، 2، 3 ـــ فالأطفال لا يتعُّمون هذه الخصيصة. أما إن لم تكن المبادئ الأساسيّة لهذه الخصيصة موجودة بشكل

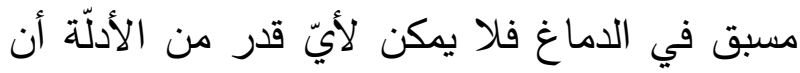
يوفّرهاه آفاق جديدة في دراسة اللغة والذهن، ترجمة:

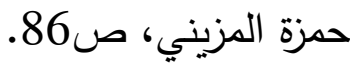
(33) انظر : تشومسكي، آفاق جديدة في دراسة اللغة والذهن، ترجمة: حمزة الززيني، ص85. (34) انظر : ليونز ، نظريّة تشومسكي اللغوية، ترجمة: حلمي خليل، ص208. ومصطفى التوني، المدخل السلوكيّ لدراسة اللغة في ضوء المدارس والاتّجاهات

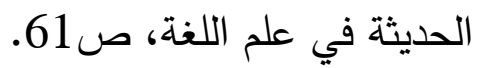

نكتفي بإبراز التحوّل الإبستمولوجيّ الذي وقع في علم اللسانيّات مع ظهور الاتِّاه التوليديّ. (26) انطلاقًا من هذه الإثارة نلحظ أن نشومسكي كان يساجل خصومه في حقول معرفية من خارج اللسانيات، مثل: (سكينر) و (بياجيه) وغيرهما؛ لأنهم يؤسّسون نظرياتهم على المرجعيّات المعرفيّة نفسها التي قامت عليها اللسانيّات البنيويّة. (27) انظر: محمد العمري، الأسس الإبستمولوجيّة للنظريّة اللسانيّة البنيويّة والتوليديّة، ص129. (28) نظريّات العلم، آلان شالمرز، ترجمة: الحسين سحبان وفؤاد الصفا، ص18. (29) قال أبو حامد الغزالي: 》انتهى بي طول التشكّك إلى أن لم تسمح نفسي بتسليم الأمان في المحسوسات

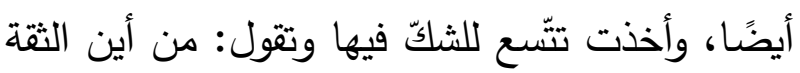
بالمحسوسات، وأقواها حاسّة البصر ؟ وهي تتظر إلى إنى الظلّ فتراه واقفًا غير متحرّك، وتحكم بنفي الحركة، ثم بالتجربة والمشاهدة بعد ساعة تعرف أنه متحرك، وأنه لم يتحرك دفعة واحدة بغتة، بل على التدريج ذرة ذرة حتى لم يكن له حالة وقوف《. المنقذ من الضلال والموصل إلى ذي العزّة والجلال، ص33. وقال شالمرز : الدينا عناصر عديدة تثير إلى أنّ التجربة التي يعيشها ملاحظون ينظرون إلى شيء ما لا لا لإنى تحددها مجرد المعلومات التي يتمّ نقلها على شكل أشعة ضوئية تدخل الأعين، ولا تحددها الصور التي ترتسم فوق الثبكية فقطز وإنّ ملاحظين عاديين يريان شيئا واحدًا من موقع واحد وفي شروط فيزيائية واحدة 
اشتراكها في مبادئ معيّنة تتمثّل في وظيفة اللسان الطبيعيّ الأساسيّة والاهتمام بالمكوّن التداوليّ والانطلاق من خصائص الوظائف التداوليّة لتحليل البنية الصرفيّة والتركيبيّة؛ فقد جعلها ذلك تلتقي في التي التئي التسمية بـ(الوظيفيّة)، فيمكن أن نقول إنّ في اللسانيّات وظيفيّات لا وظيفيّة. وكانت هذه الوظيفيّات توجد منذ ثلاثينيّات القرن الماضي وتسير في تطوّرها مع التطوّرات التي حدثن في اللسانيّات بشكل عامّ. ونلزم أنفنا في هذا البحث بدراسة (الوظيفيّة) التي تبنّاها

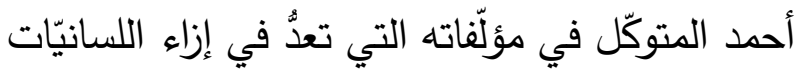
الصوريّة بحسب ما يظهره البحث بينها وبين تلك لك اللسانيّات من اختلاف في المنطلقات النظريّة. ولمزيد من التوسّع في هذه الوظيفيّات انظر : يحيى بعيطيش،

نحو نظريّة وظيفيّة للنحو العربيّ، صبئية 35-75. (44) انظر : أحمد المتوكّل، اللسانيّات الوظيفيّة:

$$
\text { مدخل نظريّ، ص14 (14-16. }
$$

(45) إذا أخذنا النحو الوظيفي الذي قدّمه (سيمون ديك) عام 1978م ثم واصل العمل فيه أحمد المتوكّل فإنّ في هذا الاتّجاه تمييزًا بين مرحلتين رغم أنهما يشتركان في المبادئ النظريّة نفسها: 1-نموذج الجملة ظهر 1978م. 2-نموذج النصّ ظهر 1989م. (46) نلاحظ أنّ محافظة تشومسكي على مبادئه الكبرى منذ انطلاقة نظريته في منتصف خمسينيّات

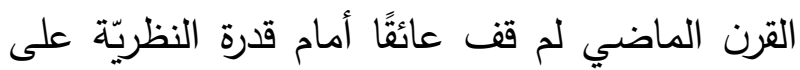
تجاوز قصورها باحتواء التصوّرات المضادّة التي طوّرت النظريّة ودفعتها للتقدّم أكثر مما عرقلت
(35) انظر: محمد العمري، الأسس الإبستمولوجيّة للنظريّة اللسانيّة البنيويّة والتوليديّة، ص221. (36) انظر: محمد العمري، الأسس الإبستمولوجيّة للنظريّة اللسانيّة البنيويّة والتوليديّة، صعري، النسئ (37) للتوسّع في بيان هذا القصور نحيل القارئ إلى: مصطفى غلفان، اللسانيات التوليديّة، 110/1 وما تأسّست اللسانيّات التوليديّة على إحياء عدد من التأملات والأفكار التقليديّة من ميادين مختلفة، كالفلسفة واللغة والفيزياء، بعد أن يعيد (تشومسكي) صياغتها ومناقشتها والاستدلال لها في ضوء ما يتيحه له البحث العلميّ المعاصر، من ذلك حضور أفكار (أفلاطون)، و (ديكارت)، و(هامبولت) وغيرهم في كثير من مؤلفات (تثومسكي). تشومسكي، آفاق جديدة في اللغة والذهن،

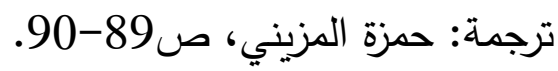
(40) يتلخّص مشكل أفلاطون في البحث عن تفسير لكفارقة محيّرة في نظريّة المعرفة، وملخّصها: كيف يكون لاى الإنسان هذا القدر الكبير من المعرفة رغم

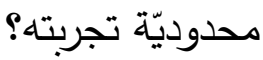
(41) انظر : تشومسكي، آفاق جديدة في دراسة اللغة والذهن، ترجمة: حمزة المزيني، صوب-91-91. تشومسكي، آفاق في دراسة اللغة والذهن، ترجمة: حمزة المزيني، ص88. (43) نذكّر بأن مصطلح (الوظيفيّة) يحيل إلى عدد الهئ من الدفاهيم التي تختلف فيما بينها نظريًّا وزمانيًّا رغم لئي 
دولة غير منشورة، جامعة منتوري قسنطينة، الجزائر، السنة الجامعية 2005-2006م.

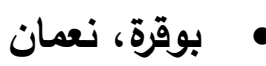
الدراسات اللسانيّة في المملكة العربيّة السعوديّة: دراسة وصفيّة تأصيليّة في ضوء التلقّي العربي للمناهج اللسانيّة الحديثة، عالم الكتب الحديث، إربد، ط1، .2011

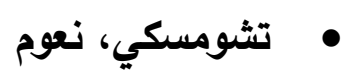

1. آفاق جديدة في دراسة اللغة والذهن، ترجمة حمزة

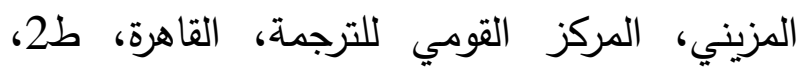
2015

2. البنى النحويّة، ترجمة يؤيل يوسف عزيز، دار الثؤون الثقافية العامة، بغداد، ط1، 1987م. 3. اللسانيات التوليدية: من التفسير إلى ما وراء التفسير، ترجمة محمد الرحالي، دار الكتاب الجديد المتحدة، بيروت، ط1، 2013م.

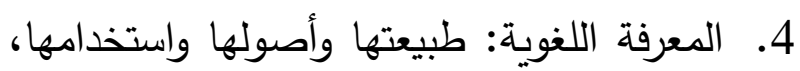
ترجمة محمد فتيح، دار الفكر العربي، القاهرة، ط1، واهُ 1993

\section{• التوني، مصطفى}

المدخل السلوكيّ في دراسة اللغة في ضوء المدارس والاتجاهات الحديثة في علم اللغة، حوليات كلية الآداب، جامعة الكويت، الحوليّة العاشرة، 1989م.

$$
\text { • تيبس، يوسف جابه }
$$

التصوّرات العلميّة للعالم: قضايا واتجاهات في فلسفة العلم المعاصرة، ابن النديم للنشر والتوزيع، الجزائر ،
مسيرتها، وتبعًا لذلك تصعب المجازفة بالقطع بموقف نهائيّ للنظريّة تجاه الوظيفة والقصد، ولكن الإثارة هنا لموقف تاريخيّ تجاوزته النظريّة مع البرنامج الأدنويّ

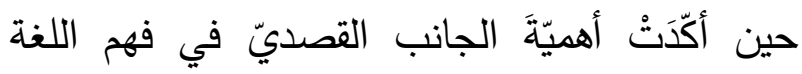

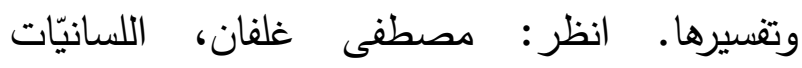
التوليديّة، ص456. وتشومسكي، اللسانيّات التوليديّة: من التفسير إلى ما وراء التقسير، ترجمة: محمد

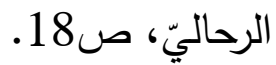

(47) سيرل، تشومسكي والثورة اللغويّة، ص134. (48) جعل (رومان جاكبسون) للغة ستّ وظائف، وجعل (هاليداي) للغة ثلاث وظائف. انظر : أحمد

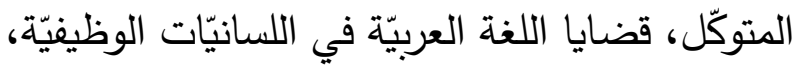

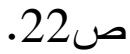
(49) انظر : أحمد المتوكّل، قضايا اللغة العربيّة في اللسانيّات الوظيفيّة، ص23. (50) انظر : أحمد المتوكّل، قضايا اللغة العربيّة في اللسانيّات الوظيفيّة، ص23. (51) انظر : أحمد المتوكّل، قضايا اللغة العربيّة في اللسانيّات الوظيفيّة، ص24-27. المصادر والمراجع

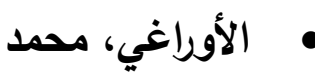
الوسائط اللغويّة: أفول اللسانيّات الكليّة، دار الأمان، الرباط، ومنشورات الاختلاف، الجزائر، ومنشورات الاختلاف، الرياض، ط2، 2013م.

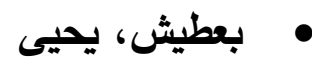

نحو نظرية وظيفية للنحو العربي، أطروحة دكتوراه 
والتوليدية، دار أسامة للنشر ، ط1، عمّان، 2012م.

$$
\text { الغزالي، أبو حامد }
$$

المنقذ من الضلال والموصل إلى ذي العزّة والجلال، دار كيرانيس للطباعة والنشر، الزيتونة، ط2،

\section{• غلفان، مصطفى}

اللسانيات البنيوية: منهجيات واتجاهات، دار الكتاب الجديد المتحدة، بيروت، ط1، 2013م.

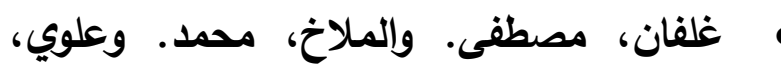

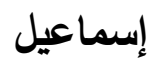
1. اللسانيات التوليدية من النموذج ما قبل المعيار

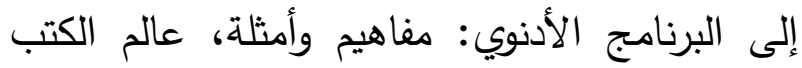

$$
\text { الحديث، ط1، الأردن، 2010م. }
$$

2. اللسانيات العربية الحديثة: دراسة نقديّة في المصادر والأسس النظريّة والمنهجيّة، سلسلة رسائل وأطروحات رقم 4، كلية الآداب والعلوم الإنسانيّة، جامعة الحسن الثاني - عين الثق.

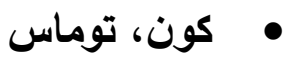

بنية الثورات العلميّة، ترجمة شوقي جلال، منشورات عالم المعرفة، الكويت، ديسمبر 1992م.

$$
\text { • ليونز، جون }
$$

نظرية تشومسكي اللغوية، ترجمة حلمي خليل، دار

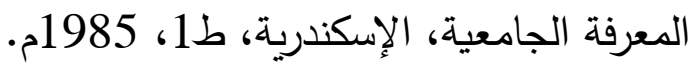

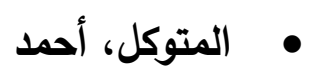

1. قضايا اللغة العربية في اللسانيات الوظيفية، دار

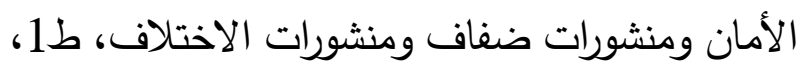

ودار الروافد الثقافية، لبنان، ط1، 2014م.

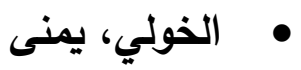

1. فلسفة العلم في القرن العشرين، منشورات عالم المعرفة، الكويت، 2000م.

2. مشكلة العلوم الإنسانيّة: تقنينها وإمكانيّة حلها، نيو بوك للنشر والتوزيع، القاهرة، ط8، 2018م.

$$
\text { دي سوسير ، فردينان }
$$

دروس في الألسنية العامة، ترجمة صالح القرمادي لرديان ومحمد الثاوش ومحمد عجينة، الدار العربية للكتاب.

$$
\text { • راسل، برتراند }
$$

النظرة العلميّة، ترجمة عثمان نويه، دار المدى للثقافة والنشر ، بغداد، ط1، 2008م.

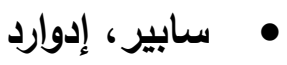

اللغة: مقدمة في دراسة الكلام، ترجمة المنصف عاشور، الدار العربية للكتاب، تونس، ط2، دراسه، 1997م. • سامسون، جفري مدارس اللسانيات: التسابق والتطور ، منشورات جامعة الملك سعود، الرياض، 1417هـ.

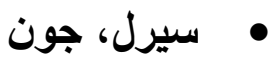
تثومسكي والثورة اللغوية، مجلة الفكر العربيّ، معهد الإنماء العربيّ، لبنان، عدد 8-9، مارس 1979م.

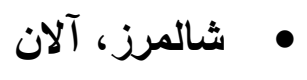

نظريات العلم، ترجمة الحسين سحبان وفؤاد الصفا، دار توبقال، ط1، الدار البيضاء، 1991م. • العمري، محمد محمد

الأسس الإبستمولوجية للنرية اللسانية البنيوية 


$$
\text { • عدد 2، مجلد 29، الكتلالي، محمد. وبيقي، - ديسمبر 2000م. }
$$

معايير العلميّة، نصوص مختارة ومترجمة، دار توبقال

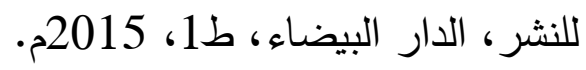

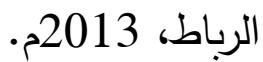

2. اللسانيات الوظيفية: مدخل نظري، دار الكتاب الجديد المتحدة، ط2، بيروت، 2010م. • نفادي، السيد التقدم العلميّ ومشكلاته، مجلة عالم الفكر، الكويت، 


\title{
Evolution of the scientific and linguistic paradigm from structuralist, generative, and functionalist perspectives
}

\author{
Dr. Muaath Al-Dukhil, \\ Assistant Professor of Linguistics, \\ Department of Arabic Language and Literature, \\ College of Arabic Language and Social Studies, Qassim \\ University, Saudi Arabia.
}

\begin{abstract}
. the present research is aims to sort out the epistemological changes in the field of linguistics in the domain of the relationship between the phenomenon and the scientific theory that explains it. In order to achieve this goal, we looked at the developments concurred by the scientific and linguistic paradigm in the structuralist, generativist, and functionalist directions. The research has shown that the changes in the linguistic course in each perspective and has determined the departures of each perspective form a point of view of it's the nature of the object of study and the hypotheses set forward in order to treat the data therein. The research has shown that structuralist linguistics has different characteristics when seen from the European structuralist school and the American structuralist one to the extent that one might think structuralism has different scientific paradigms. However, we found that the difference in paradigm is the angle from which we see language. Do we see language as a natural phenomenon or social phenomenon different from any biological phenomena?

Generative linguistics, on the other hand, is a scientific revolution against the vision of science as the mere collection of data and its organization and linking of its laws to experience and practice. This paradigm puts data on secondary level of importance in science. Thus, generative linguistics gave away any link to language use and attributed facts to an ideal speaker, all in accordance with its theoretical background.

The scientific functionalist paradigm is built upon the principle that structure belongs to function. Thus, the object of study in linguistics in the functionalist paradigm is the communicative competence, which is opposed to linguistic competence in generative grammar. Consequently, the functionalist paradigm has introduced pragmatic explanation into linguistics in order to study the structure of language.
\end{abstract}

Key words: Linguistics, scientific paradigm, structural linguistics, generative linguistics, functional linguistics. 